\title{
An Analysis of Perfect-Magnetic-Coupling Ultra-Low-Loss Micromachined SMIS RF Transformers for RFIC Applications
}

\author{
Hsiao-Bin Liang, Yo-Sheng Lin, Senior Member, IEEE, Chi-Chen Chen, Po-Feng Yeh, Yan-Ru Tzeng, \\ Tao Wang, and Shey-Shi Lu, Senior Member, IEEE
}

\begin{abstract}
Selective removal of the silicon underneath a set of single-turn multilayer interlaced stacked (SMIS) radio-frequency (RF) transformers with nearly perfect magnetic-coupling factor $\left(k_{\mathrm{IM}} \sim 1\right)$ and high resistive-coupling factor $\left(k_{\mathrm{Re}}\right)$ is demonstrated. This process is based on the inductively coupled-plasma (ICP) deep trench technology. Improvement of 20.6 and $15.7 \mathrm{~dB}$ in isolation $\left(S_{21}\right)$ were achieved at 5.2 and $8 \mathrm{GHz}$, respectively, for a dummy open device after the backside ICP etching. $Q$-factor increases of $102 \%$ (from 4.96 to 10.03 ) and $23.2 \%$ (from 2.24 to 2.76), $G_{A \max }$ increases of $11.8 \%$ (from 0.76 to 0.85 ) and $4.5 \%$ (from 0.88 to 0.92 ), and $\mathrm{NF}_{\text {min }}$ decreases of $0.49 \mathrm{~dB}$ (from 1.22 to $0.73 \mathrm{~dB}$ ) and $0.19 \mathrm{~dB}$ (from 0.55 to $0.36 \mathrm{~dB}$ ) were achieved at 5.2 and $8 \mathrm{GHz}$, respectively, for an SMIS transformer with an overall dimension of $170 \times 240 \mu \mathrm{m}^{2}$ after the backside ICP etching. The $G_{A \text { max }}$ of 0.85 and 0.92 are both state-of-the-art results among all reported on-chip transformers. Furthermore, the reasons why the SMIS transformer exhibits better performances than the traditional bifilar and the traditional stacked transformer are explained. These results show that the micromachined SMIS transformers are very promising for RF integrated circuit applications.
\end{abstract}

Index Terms-Inductively coupled plasma (ICP), magnetic coupling, quality factor ( $Q$-factor), radio-frequency integrated circuit (RFIC), single-turn multilayer interlaced stacked (SMIS), transformer, ultra-low-loss.

\section{INTRODUCTION}

$\mathbf{R}$ ECENTLY, mixed-signal/radio-frequency (RF) CMOS and BiCMOS processes have become more and more popular for RF integrated circuits (ICs) operated in the $5-\mathrm{GHz}$ band [1], [2] and even in the higher 24-100-GHz bands [3]-[6]. In the design of ultra-low-voltage and high-performance voltage-controlled oscillators (VCOs) [7], [8] and low-noise

Manuscript received March 16, 2006; revised May 20, 2006. This work was supported by the National Science Council of the R.O.C. under Contract NSC95-2212-E-260-001, Contract NSC94-2212-E-260-002, Contract NSC93-2212-E-260-003, Contract NSC92-2212-E-002-091, Contract NSC92-2212-E-260-001, Contract 1EC17A05-S10017, and Contract NSC93-2752-E-002-002-PAE.

H.-B. Liang, Y.-S. Lin, C.-C. Chen, P.-F. Yeh, and Y.-R. Tzeng are with the Department of Electrical Engineering, National Chi Nan University, 545 Puli, Taiwan, R.O.C..

T. Wang and S.-S. Lu are with the Graduate Institute of Electronics Engineering and Department of Electrical Engineering, National Taiwan University, 106 Taipei, Taiwan, R.O.C. (e-mail: sslu@ntu.edu.tw).

Color versions of Figs. 3 and 4 and Tables II-IV are available online at http:// ieeexplore.ieee.org.

Digital Object Identifier 10.1109/TMTT.2006.885901 amplifiers (LNAs) [9], the power gain $G_{A}$ [or noise figure (NF)] performance of the transformers used is crucial for the phase noise performance of the VCOs and the NF performance of the LNAs. However, the $G_{A}$ (or NF) performance of monolithic RF transformers fabricated on normal silicon substrates $(\sim 300 \mu \mathrm{m})$ is usually not satisfactory mainly due to the silicon substrate loss and the magnetic-coupling factor $\left(k_{\mathrm{IM}}\right)$, which is not sufficiently high. Various methods have been proposed to reduce the silicon substrate loss of RF passive devices, such as the adoption of high-resistivity silicon substrate [10], front-side and backside micromachining [11]-[16], making silicon substrate porous [17]-[19], proton implantation [20], substrate transfer [21], and silicon substrate thinning [22]. However, most of the proposed methods are very difficult, if not impossible, to be integrated into the standard CMOS technology due to their inherent nonstandard CMOS processing steps. For example, all of the classical micromachining techniques in [11]-[16] include at least a wet-etching process step, which is not compatible with the standard CMOS technology. For large-diameter (4-12-in) wafers used in the industry, it is very difficult (or nearly impossible) to uniformly thin down the silicon substrate to about $20 \mu \mathrm{m}$ (just like that in [22] to reduce the silicon substrate loss) without breaking it. In addition, the patterned ground shields (PGSs) method, while being compatible with CMOS technology, has the drawbacks of limited improvement of $Q$-factor and reduction of self-resonant frequency $\left(f_{\mathrm{SR}}\right)$. Fortunately, these problems can be improved to a large extent by our proposed backside inductively coupled-plasma (ICP) deep trench technology, which has been successfully applied to improve the performances of RF inductors [23] and their RFICs [24], [25]. Compared with the traditional backside wet bulk micromachining in [13], the dry ICP etching has the advantages of forming vertical sidewalls and being fully CMOS-process-compatible since it is a standard processing technique in modern CMOS technology.

In addition, recently, it has been demonstrated that high $k_{\mathrm{IM}}(\sim 0.92)$ can be obtained by using an exactly stacked (i.e., no offset between the primary coil and the secondary coil) single-turn transformer structure with a very small vertical distance (VD) of $0.04 \mu \mathrm{m}$. The very small VD is achieved by using the top (CTM) and the bottom metal layer (M5) of the metal-insulator-metal (MIM) capacitor, respectively, as the primary and secondary coils of the transformer [26]. However, this structure suffers from low $Q$-factor performance of the primary coil mainly due to its thin CTM layer $(\sim 0.15 \mu \mathrm{m})$. 
In addition, large parasitic capacitance exists between the primary and secondary coils, which degrades the $Q$-factor performance of both the primary and secondary coils.

Therefore, in this study, the single-turn multiple-layer interlaced stacked (SMIS) transformer structure which can overcome the abovementioned drawbacks and achieve a nearly perfect magnetic-coupling factor $\left(k_{\mathrm{IM}} \sim 1\right)$, and a high resistive-coupling factor $\left(k_{\mathrm{Re}}\right)$ is adopted [27]-[30]. $k_{\mathrm{IM}} \sim 1$ and high $k_{\mathrm{Re}}$ are obtained because the equivalent VD of the SMIS structure is roughly zero. Besides that, the CMOS-compatible backside ICP deep trench technology, which selectively completely removes the conductive silicon substrate underneath the transformers, is used to reduce the silicon substrate loss (or to improve the $Q$-factor performances of both the primary and secondary coils). In our previous work [31], only two SMIS transformers for 5-GHz-band applications are briefly introduced. In this study, we give a detailed investigation of a complete set of SMIS transformers with operation frequency up to $40 \mathrm{GHz}$. In addition, some simulation and modeling data are added and discussed.

In Section II, the backside ICP deep trench technology is introduced. In Section III, a detailed description of the transformer structures studied in this paper (including the SMIS transformer, a traditional stacked transformer, and a traditional bifilar transformer) is presented. In Section IV, a complete small-signal model of a transformer on silicon is proposed. Some analytical expressions are derived to explain the measurement results of the transformers. In Section V, we demonstrate the measurement results and provide some discussions. Satisfactory results are obtained for SMIS transformers for 5-GHz-band wireless local access network (WLAN) and $K a$-band (26-40 GHz) RFIC applications. A comparison of the SMIS transformer with the traditional stacked transformer and the traditional bifilar transformer is also given. Section VI presents the conclusions.

\section{DeEP TREnCh TeChNOlogy}

The processing steps of our backside ICP deep trench technology are shown in Fig. 1 and are described as follows. First, for the ease of chip handling, the front side of the die $(\sim 5 \mathrm{~mm} \times$ $5 \mathrm{~mm}$ ) with transformers was mounted to a glass substrate with S1813 adhesive. This process step can be omitted when applied in mass production because the wafer diameter is large. Then, the silicon substrate was thinned down to about $100 \mu \mathrm{m}$ by mechanical lapping. Second, the wax was softened by heating, so that the glass substrate in the front-side of the die could be removed. Then, the die was cleaned with acetone followed by mounting the front-side of the $100-\mu \mathrm{m}$-thick die to a glass substrate with S1813 adhesive. The reason why the die was removed from the glass to do the cleaning process and then remounted for further processing is explained as follows. If the chip had not been removed from the glass substrate in advance, in the cleaning process with acetone, part of the adhesive on the front-side of the die would have dissolved and polluted the backside of the die. Third, photoresist SU8 was spun on the backside of the sample. After standard photolithography processing on the backside of the die, the ICP dry etching was used to remove the silicon underneath the transformers. The main gases

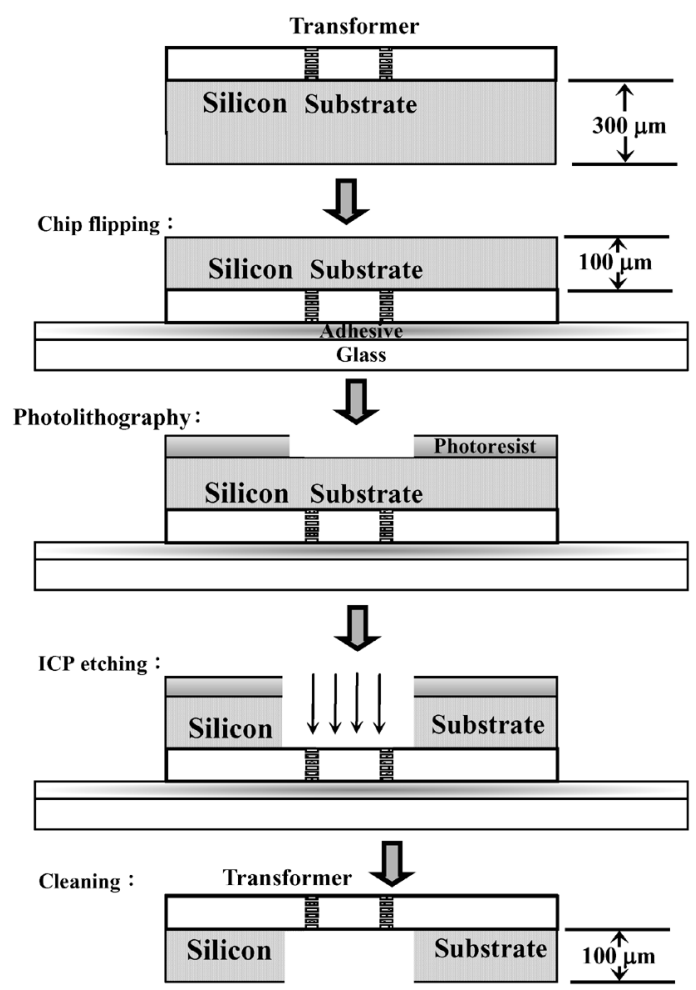

Fig. 1. Process steps of the backside ICP deep trench etching technology suitable for a small-area chip such as the one is in this study.

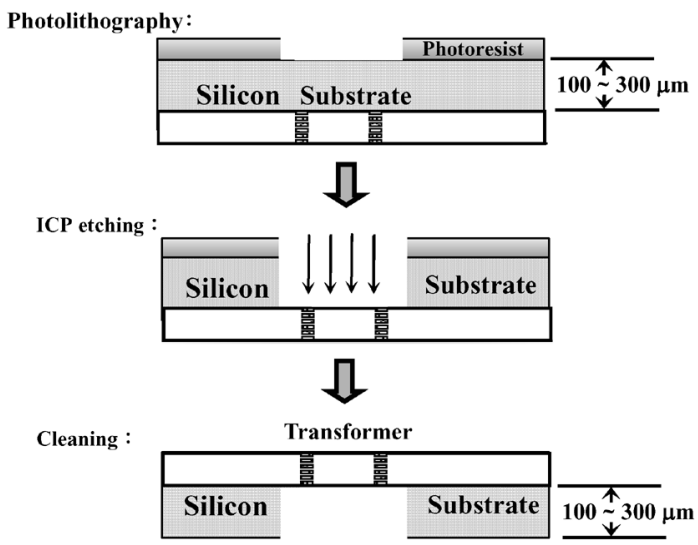

Fig. 2. Process steps of the backside ICP deep trench etching technology suitable for large-diameter (4-12 in) wafers in the industry.

used during the ICP etching process were alternate $\mathrm{SF}_{6}$ (for etching) and $\mathrm{C}_{4} \mathrm{~F}_{8}$ (for passivation) with a 17 -s cycle. Since the ICP etching rate was approximately $2 \mu \mathrm{m} / \mathrm{min}$, the total etching time was approximately $50 \mathrm{~min}$. Finally, the adhesive and photoresist which covered the front-side and the backside of the die, respectively, were removed for test purpose. For the present small $5 \mathrm{~mm} \times 5 \mathrm{~mm}$ chip, it is found that the yield is $100 \%$ in the laboratory. Note that the first two process steps, i.e., thinning the silicon substrate from 300 to $100 \mu \mathrm{m}$, can be omitted to simplify the process [25] and to avoid breaking the large-diameter wafers in the industry. The price to be paid is the increase of the total etching time to about 150 min because the silicon substrate to be etched is $300-\mu \mathrm{m}$ thick. In addition, for large-diameter wafers used in the industry, etching uniformity becomes 


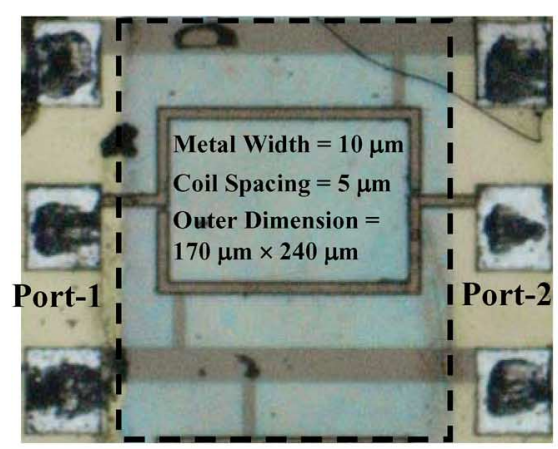

(a)

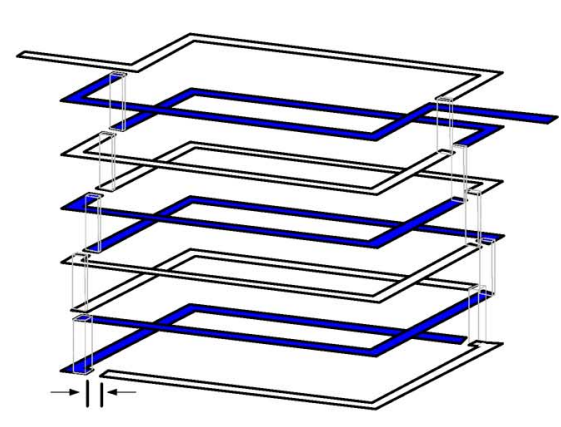

(b)

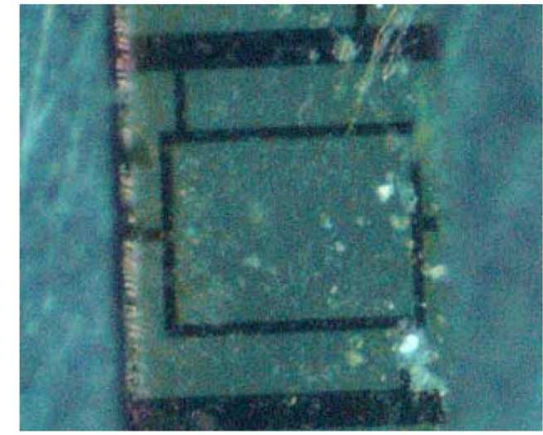

(c)

Fig. 3. (a) Top-view die photograph, (b) 3-D schematic diagram, and (c) backside die photograph of a six-layer SMIS transformer with metal width of $10 \mu \mathrm{m}$ and overall dimension of $170 \mu \mathrm{m} \times 240 \mu \mathrm{m}$. The layout parameters of the transformer are also shown in (a).

a serious issue. A feasible solution is adding an etching stopping layer with high etching selectivity (e.g., $\mathrm{SiO}_{x} \mathrm{~N}_{y}$ ) below the transformers in the front-end of the CMOS process [i.e., on the top of shallow trench isolation (STI)].

In addition, mounting the silicon wafer on a carrier (glass) substrate (for ease of handling the ICP etching) induces some factors for nonuniformity, such as planarization, temperature control, and air pockets between glass and silicon. Fortunately, for large-diameter wafers adopted in the industry, no carrier substrate is needed, so the abovementioned factors for nonuniformity do not exist. Fig. 2 shows the process steps of the backside ICP deep trench etching technology suitable for large-diameter wafers in the industry. Because ICP is a standard process technique in modern CMOS technology, the process steps in Fig. 2 are compatible with the standard RFIC process.

\section{TRANSFORMER STRUCTURE}

The SMIS transformers under study were fabricated with an $0.18-\mu \mathrm{m}$ mixed-signal/RF CMOS technology on a p-type silicon substrate (resistivity: $10 \Omega \cdot \mathrm{cm}$ ) with thickness of $300 \mu \mathrm{m}$. The main features of the back-end processes are as follows. There are six metal layers M1-M6 from the bottom to the top. The thickness of M6 is $0.99 \mu \mathrm{m}$ and that of M1-M5 is $0.53 \mu \mathrm{m}$. The oxide thickness between M6 and M5, between other adjacent metal layers, and between M1 and the silicon substrate is $1,0.85$, and $0.75 \mu \mathrm{m}$, respectively.

A set of two-layer, four-layer, and six-layer SMIS transformers with various metal widths $(1.5,3,9.5$, and $10 \mu \mathrm{m})$ and various inner dimensions $\left(50 \times 50 \mu \mathrm{m}^{2}, 100 \times 100 \mu \mathrm{m}^{2}\right.$, $150 \times 150 \mu \mathrm{m}^{2}, 141 \times 211 \mu \mathrm{m}^{2}$, and $150 \times 220 \mu \mathrm{m}^{2}$ ) were fabricated and studied. The key layout parameters and extracted parameters (will be discussed in Sections IV and V) of some representative transformers are summarized later. Fig. 3(a) and (b) shows the top-view die photograph and the three-dimensional (3-D) schematic diagram of a six-layer SMIS transformer with a metal width of $10 \mu \mathrm{m}$, coil spacing (between the primary and secondary coils) of $5 \mu \mathrm{m}$, and inner dimension of $150 \mu \mathrm{m} \times 220 \mu \mathrm{m}$ (or overall dimension of $170 \mu \mathrm{m} \times 240 \mu \mathrm{m})$. Port-1 and Port-2 stand for the input and output ports of the network analyzer, respectively. Some of the transformers have gone through the CMOS-compatible backside ICP dry etching so that the silicon substrate effect on the performances of the transformers could be studied.
Specifically, the silicon substrate below the rectangular area surrounded by the dash line as indicated in Fig. 3(a) was fully dry etched away. After the removal of the backside silicon, the thickness of the transformer structure was about $9.14 \mu \mathrm{m}$. Because the transformers-on-air are connected to silicon substrate with a thickness of 100-300 $\mu \mathrm{m}$, their mechanical stability and structure reliability should be no problem. Fig. 3(c) shows the backside die photograph of the six-layer SMIS transformer, where the exposed front-side on-chip transformer is visible to the naked eye and the sidewalls of the "drilled" or micromachined holes are virtually vertical.

For comparison, a traditional vertically stacked transformer was also fabricated by the same $0.18-\mu \mathrm{m}$ CMOS technology. Its top-view photograph and layout parameters are shown in Fig. 4(a). Fig. 4(b) shows the 3-D schematic diagram of the stacked transformer. To minimize the parasitic capacitance between the primary and the secondary coil, the primary turns are offset with respect to the secondary turns [32]. In addition, a traditional bifilar transformer was also fabricated with a $0.35-\mu \mathrm{m}$ SiGe BiCMOS technology on a p-type silicon substrate with thickness of $318 \mu \mathrm{m}$ and resistivity of $10 \Omega \cdot \mathrm{cm}$. Its top-view photograph and layout parameters are shown in Fig. 4(c). Fig. 4(d) shows the backside die photograph of the bifilar transformer after the backside ICP etching. The main features of the back-end processes of the BiCMOS technology are as follows. There are three metal layers. We name the metal layers M1-M3 from the bottom to the top. The thickness of M3 is $3.05 \mu \mathrm{m}$ and that of M1 and M2 is $0.665 \mu \mathrm{m}$. The oxide thickness is $1 \mu \mathrm{m}$ between adjacent metal layers and $1.1 \mu \mathrm{m}$ between $\mathrm{M} 1$ and the silicon substrate. The reason why this technology was adopted is because of its thick top metal of $3.05 \mu \mathrm{m}$, which is beneficial for improving the performance of the bifilar transformer. We will demonstrate later that the performance of a SMIS transformer with thin top metal of $0.99 \mu \mathrm{m}$ is even better than that of the bifilar transformer with a thick top metal of $3.05 \mu \mathrm{m}$.

\section{SMall-Signal Model AND SOME Useful Expressions}

Fig. 5(a) shows our proposed complete small-signal equivalent circuit model of the transformers. The inductor model in [33], which models the silicon substrate loss by transformer loops, was adopted to model both the primary and secondary coil inductors of the transformers. The transformer loops, including resistances $R_{m s 1 i}$ and $R_{m s 2 i}$, inductances $L_{m s 1 i}$ and 


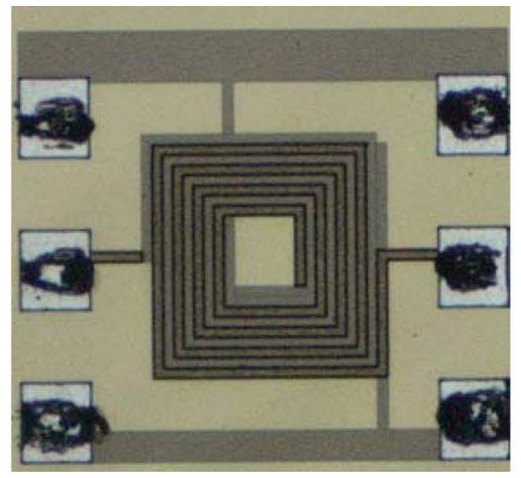

\begin{tabular}{|c|c|}
\hline $\begin{array}{c}\text { Transformer } \\
\text { Structure }\end{array}$ & $\begin{array}{c}\text { Traditional } \\
\text { Stacked 3D }\end{array}$ \\
\hline Metal Width $(\mu \mathrm{m})$ & 10 \\
\hline Metal Space $(\mu \mathrm{m})$ & 10 \\
\hline $\begin{array}{c}\text { Turn Number } \\
\text { Per Layer }\end{array}$ & 4 \\
\hline Turn Ratio & $1: 2$ \\
\hline $\begin{array}{c}\text { Overall Dimension } \\
(\mu \mathrm{m} \times \mu \mathrm{m})\end{array}$ & $240 \times 240$ \\
\hline $\begin{array}{c}\text { Inner Dimension } \\
(\mu \mathrm{m} \times \mu \mathrm{m})\end{array}$ & $60 \times 70$ \\
\hline
\end{tabular}

(a)

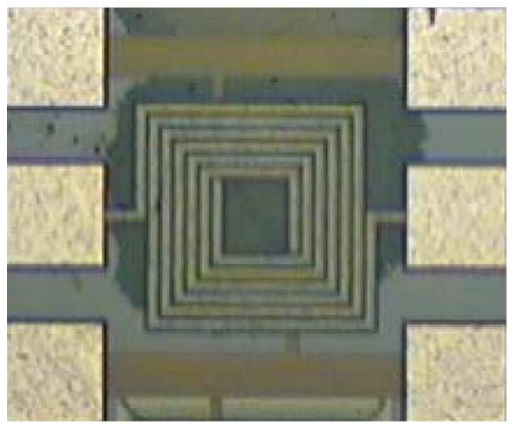

\begin{tabular}{|c|c|}
\hline $\begin{array}{c}\text { Transformer } \\
\text { Structure }\end{array}$ & $\begin{array}{c}\text { Traditional } \\
\text { bifilar }\end{array}$ \\
\hline Metal Width $(\mu \mathrm{m})$ & 10 \\
\hline Metal Space $(\mu \mathrm{m})$ & 2 \\
\hline Top Metal THK $(\mu \mathrm{m})$ & 3.05 \\
\hline Turn Ratio & $3: 3$ \\
\hline $\begin{array}{c}\text { Overall Dimension } \\
(\mu \mathrm{m} \times \mu \mathrm{m})\end{array}$ & $230 \times 215$ \\
\hline $\begin{array}{c}\text { Inner Dimension } \\
(\mu \mathrm{m} \times \mu \mathrm{m})\end{array}$ & $73 \times 62$ \\
\hline
\end{tabular}

(c)

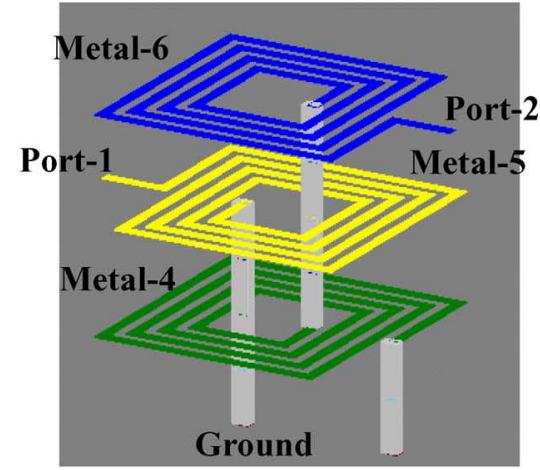

(b)

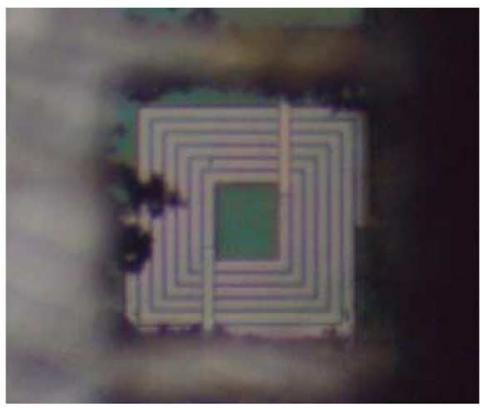

(d)

Fig. 4. (a) Top-view die photograph and layout parameters and (b) 3-D schematic diagram of a stacked transformer with a turn ratio of 1:2. (c) Top-view die photograph and layout parameters and (d) backside die photograph of a bifilar transformer with a turn ratio of 3:3.

$L_{m s 2 i}$, and mutual inductances $M_{s 1 i}$ and $M_{s 2 i}$, take into account the effects of frequency-dependent loss in the silicon substrate, such as substrate skin effect and eddy current loss. The mutual inductances $M_{s 1 i}$ and $M_{s 2 i}$ can be viewed as partly representing the inductive coupling between the spiral metal wires and the semi-conducting silicon substrate. In addition, $L_{\mathrm{si}}$ and $R_{\mathrm{si}}$ represent the self-inductance and resistive loss on the metal coils. $L_{\mathrm{ski}}$ and $R_{\mathrm{ski}}$ model the skin effects of the metal coils at high frequencies. $C_{s 1}$ and $C_{s 2}$ model the parasitic capacitance consisting of the overlap capacitance (between the primary and secondary coils) and the fringing capacitance (between metal wires) of the primary and secondary coils, respectively. The oxide capacitance between the metal wires and the substrate is modeled by $C_{\mathrm{ox} 1}$ and $C_{\mathrm{ox} 2} \cdot\left(R_{\mathrm{sub} 1}, C_{\mathrm{sub} 1}\right)$ and $\left(R_{\mathrm{sub} 2}, C_{\mathrm{sub} 2}\right)$ model the loss of the silicon substrate under the primary and secondary coil inductors, respectively. Table I shows the extracted parameters of the SMIS transformer T9 both before and after the backside ICP dry etching. Because the substrate resistivity before the ICP etching $(10 \Omega \cdot \mathrm{cm})$ is not low, it is enough to include one transformer loop in the primary and secondary parts of the model to take into account the effects of frequency-dependent loss, such as substrate skin effect and eddy current loss. In addition, only the metal-line-related parameters $\left(R_{\mathrm{si}}, L_{\mathrm{si}}, R_{\mathrm{ski}}, L_{\mathrm{ski}}\right.$, and $C_{\mathrm{si}}$ ) were considered for the primary and secondary coil inductors for the transformer after the backside ICP etching because the corresponding substrate impedance is very high (i.e., substrate loss is negligible). In this study, in addition to the extraction of the small-signal parameters (i.e., modeling) from the measured $S$-parameters, full-wave electromagnetic (EM) simulation tools such as Sonnet Software's SONNET and "Mo- mentum" of Agilent's advanced design system (ADS) were used to simulate the characteristics of the SMIS transformers. Hence, the geometries of the transformer corresponding to a specific frequency-range can be derived. Fig. 6(a)-(d) shows the measured, modeled, and simulated $\operatorname{Re}\left(Z_{11}\right), \operatorname{Re}\left(Z_{12}\right), \operatorname{Im}\left(Z_{11}\right)$, and $\operatorname{Im}\left(Z_{12}\right)$ versus frequency characteristics of the SMIS transformer T9 before the backside ICP etching. As can be seen, the modeled and simulated results conform to the measured ones very well. Actually, of all the SMIS transformers studied in the study, the measured, modeled, and simulated results are all very close. This demonstrates the validity of the measured data and the created small-signal models of the SMIS transformers. A more detailed discussion will be given in Section V.

Fig. 5(b) is a simplified small-signal equivalent circuit model of the transformers. The series resistance $R_{s 1-\mathrm{eff}}$ and series inductance $L_{s 1-\text { eff }}$ of the primary coil inductor can be expressed as follows:

$$
\begin{aligned}
R_{s 1-\mathrm{eff}} \equiv & R_{s 1}-\frac{R_{s 1}^{2}\left(R_{s 1}+R_{\mathrm{sk} 1}\right)}{\left(R_{s 1}+R_{\mathrm{sk} 1}\right)^{2}+\omega^{2} L_{\mathrm{sk} 1}^{2}} \\
& +\sum_{i=1}^{N} \frac{R_{m s 1 i} M_{s 1 i}^{2} \omega^{2}}{R_{m s 1 i}^{2}+\omega^{2} L_{m s 1 i}^{2}} \\
L_{s 1-\mathrm{eff}} \equiv & L_{s 1}+L_{s k 1} \frac{R_{s 1}^{2}}{\left(R_{s 1}+R_{s k 1}\right)^{2}+\omega^{2} L_{s k 1}^{2}} \\
& -\sum_{i=1}^{N} \frac{L_{m s 1 i} M_{s 1 i}^{2} \omega^{2}}{R_{m s 1 i}^{2}+\omega^{2} L_{m s 1 i}^{2}} .
\end{aligned}
$$

The expressions of $R_{s 2-\text { eff }}$ and $L_{s 2 \text {-eff }}$ are similar to those of $R_{s 1-\mathrm{eff}}$ and $L_{s 1-\mathrm{eff}}$, respectively. Note that the series resistance 


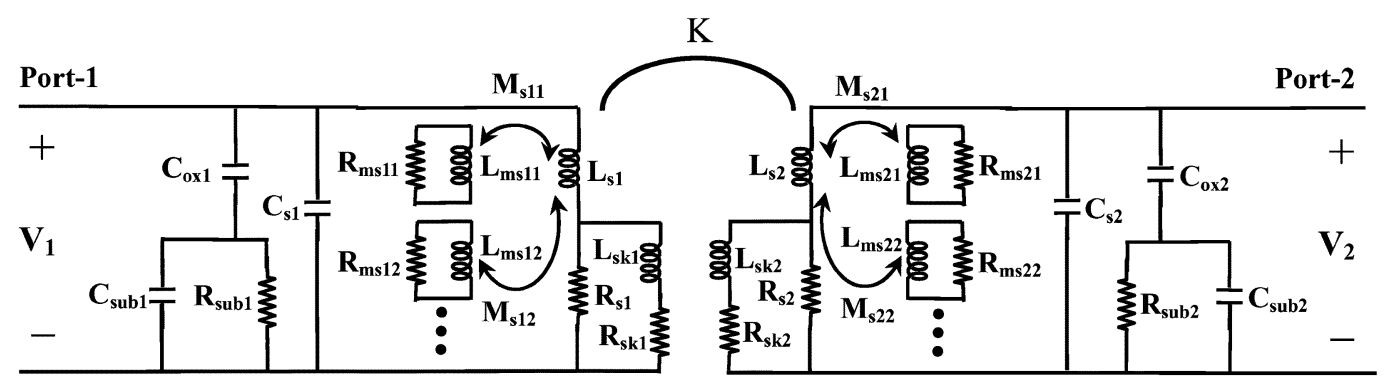

(a)

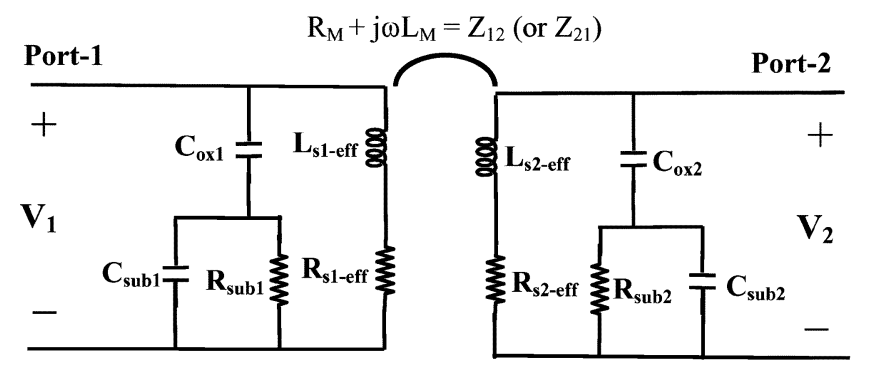

(b)
$\mathrm{R}_{\mathrm{M}}+\mathrm{j} \omega \mathrm{L}_{\mathrm{M}}=\mathrm{Z}_{12}\left(\right.$ or $\left.\mathrm{Z}_{21}\right)$

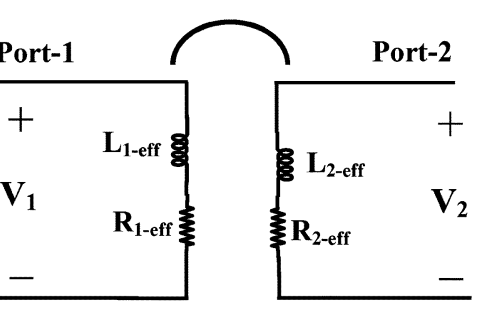

(c)

Fig. 5. (a) Complete, (b) simplified, and (c) further simplified small-signal equivalent circuit model of a transformer on a silicon substrate.

TABLE I

EXTRACTED SMALl-Signal PARAMETERS OF THE SMIS TRANSFORMER T9 BEFORE AND AFTER THE BACKSIDE ICP ETCHING

\begin{tabular}{|l|c|c|}
\hline Transformer ID & \multicolumn{2}{|c|}{ T9 } \\
\hline Overall Dimension $(\mu \mathrm{m} \times \mu \mathrm{m})$ & \multicolumn{2}{|c|}{$170 \times 240$} \\
\hline Metal Width $(\mu \mathrm{m})$ & \multicolumn{2}{|c|}{10} \\
\hline Coil Spacing $(\mu \mathrm{m})$ & \multicolumn{2}{|c|}{5} \\
\hline Metal Layer & \multicolumn{2}{|c|}{$6(\mathrm{M} 6-\mathrm{M} 1)$} \\
\hline \hline Backside ICP Etching & \multicolumn{2}{|c|}{ no } \\
\hline Frequency Range $(\mathrm{GHz})$ & \multicolumn{2}{|c|}{$\mathrm{DC}-10$} \\
\hline $\mathrm{L}_{\mathrm{s} 1}, \mathrm{~L}_{\mathrm{s} 2}(\mathrm{nH})$ & 3.35 & 3.4 \\
\hline $\mathrm{R}_{\mathrm{s} 1}, \mathrm{R}_{\mathrm{s} 2}(\Omega)$ & 14.75 & 15.4 \\
\hline $\mathrm{L}_{\mathrm{sk} 1}, \mathrm{~L}_{\mathrm{sk} 2}(\mathrm{nH})$ & 1.165 & 1.165 \\
\hline $\mathrm{R}_{\mathrm{sk} 1}, \mathrm{R}_{\mathrm{sk} 2}(\Omega)$ & 350 & 350 \\
\hline $\mathrm{M}_{\mathrm{s} 11}, \mathrm{M}_{\mathrm{s} 21}(\mathrm{nH})$ & 27 & ---- \\
\hline $\mathrm{L}_{\mathrm{ms} 11}, \mathrm{~L}_{\mathrm{ms} 21}(\mathrm{nH})$ & 2154 & ---- \\
\hline $\mathrm{R}_{\mathrm{ms} 11}, \mathrm{R}_{\mathrm{ms} 21}(\mathrm{k} \Omega)$ & 46.8 & ---- \\
\hline $\mathrm{C}_{\mathrm{s} 1}, \mathrm{C}_{\mathrm{s} 2}(\mathrm{fF})$ & 40 & 38.78 \\
\hline $\mathrm{C}_{\mathrm{ox} 1}, \mathrm{C}_{\mathrm{ox} 2}(\mathrm{fF})$ & 11.98 & ---- \\
\hline $\mathrm{C}_{\mathrm{sub1}}, \mathrm{C}_{\mathrm{sub} 2}(\mathrm{fF})$ & 124.04 & ---- \\
\hline $\mathrm{R}_{\mathrm{sub1}}, \mathrm{R}_{\mathrm{sub} 2}(\Omega)$ & 919.1 & ---- \\
\hline $\mathrm{K}$ & 1 & 0.99 \\
\hline
\end{tabular}

$R_{\text {si-eff }}(i=1,2)$ is larger than the series resistance at low frequencies $\left(R_{\mathrm{si}} \| R_{\mathrm{ski}}\right)$, while the series inductance $L_{\mathrm{si}-\mathrm{eff}}, i=$ 1,2 , is smaller than the series inductance at low frequencies $\left(L_{\mathrm{si}}+L_{\mathrm{ski}} \cdot\left(R_{\mathrm{Si}}\right)^{2} /\left(R_{\mathrm{si}}+R_{\mathrm{ski}}\right)^{2}\right)$ if the frequency-dependent loss effects are taken into account.

Fig. 5(c) shows a further simplified small-signal equivalent circuit model of the transformers. The expressions of effective series resistance $R_{1-\text { eff }}$ and effective series inductance $L_{1-\text { eff }}$ of the primary coil are as follows:

$$
\begin{aligned}
R_{1-\mathrm{eff}} & =\frac{\left[\frac{R_{s 1-\mathrm{eff}}}{R_{s 1-\mathrm{eff}}^{2}+\left(\omega L_{s 1-\mathrm{eff}}\right)^{2}}+\frac{1}{R_{p 1}}\right]^{-1}}{1+Q_{1}^{2}} \\
& \equiv \frac{R_{p 1-\mathrm{eff}}}{1+Q_{1}^{2}}
\end{aligned}
$$

$$
\begin{aligned}
L_{1-\mathrm{eff}} & =\frac{Q_{1}^{2}}{1+Q_{1}^{2}} \cdot\left[\omega^{2} C_{p 1}-\frac{\omega^{2} L_{s 1-\mathrm{eff}}}{R_{s 1-\mathrm{eff}}^{2}+\left(\omega L_{s 1-\mathrm{eff}}\right)^{2}}\right]^{-1} \\
& \equiv \frac{Q_{1}^{2}}{1+Q_{1}^{2}} \cdot L_{p 1-\mathrm{eff}}
\end{aligned}
$$

in which

$$
\begin{aligned}
Q_{1}= & \frac{\omega L_{1-\mathrm{eff}}}{R_{1-\mathrm{eff}}} \\
= & \frac{\omega L_{s 1-\mathrm{eff}}}{R_{s 1-\mathrm{eff}}} \times \frac{R_{p 1}}{R_{p 1}+\left[\left(\omega L_{s 1-\mathrm{eff}} / R_{s 1-\mathrm{eff}}\right)^{2}+1\right] R_{s 1-\mathrm{eff}}} \\
& \times\left(1-\frac{R_{s 1-\mathrm{eff}}^{2}\left(C_{p 1}+C_{s 1}\right)}{L_{s 1-\mathrm{eff}}}\right. \\
& \left.\quad-\omega^{2} L_{s 1-\mathrm{eff}}\left(C_{p 1}+C_{s 1}\right)\right) \\
R_{p 1}= & \frac{1}{\omega^{2} C_{\mathrm{ox} 1}^{2} R_{\mathrm{sub} 1}}+\frac{R_{\mathrm{sub} 1}\left(C_{\mathrm{ox} 1}+C_{\mathrm{sub} 1}\right)^{2}}{C_{\mathrm{ox} 1}^{2}} \\
C_{p 1}= & C_{s 1}+C_{\mathrm{ox} 1} \cdot \frac{1+\omega^{2}\left(C_{\mathrm{ox} 1}+C_{\mathrm{sub} 1}\right) C_{\mathrm{sub} 1} R_{\mathrm{sub} 1}^{2}}{1+\omega^{2}\left(C_{\mathrm{ox} 1}+C_{\mathrm{sub} 1}\right)^{2} R_{\mathrm{sub} 1}^{2}}
\end{aligned}
$$

The expressions of $R_{2-\text { eff }}$ and $L_{2-\text { eff }}$ are similar to those of $R_{1-\text { eff }}$ and $L_{1-\text { eff }}$, respectively. Based on the small-signal model shown in Fig. 5(c), it is convenient to use the $Z$-parameters $Z_{i j}, i, j=1,2$, to characterize the electrical properties of the transformers. The expressions of $Z_{i j}$ are as follows: $Z_{11}=R_{1-\mathrm{eff}}+j \omega L_{1-\mathrm{eff}}, Z_{22}=R_{2-\mathrm{eff}}+j \omega L_{2-\mathrm{eff}}$, and $Z_{12}=Z_{21}=R_{M}+j \omega L_{M}$. In terms of the $Z$-parameters, the maximum available power gain $G_{A \text { max }}$ is given by [21]

$$
G_{A \max }=1+2\left(x-\sqrt{x^{2}+x}\right)
$$

in which

$$
x=\frac{\operatorname{Re}\left(Z_{11}\right) \operatorname{Re}\left(Z_{22}\right)-\left[\operatorname{Re}\left(Z_{12}\right)\right]^{2}}{\left[\operatorname{Im}\left(Z_{12}\right)\right]^{2}+\left[\operatorname{Re}\left(Z_{12}\right)\right]^{2}}=\frac{1-k_{\mathrm{Re}}^{2}}{k_{\operatorname{Im}}^{2} Q_{1} Q_{2}+k_{\operatorname{Re}}^{2}}
$$




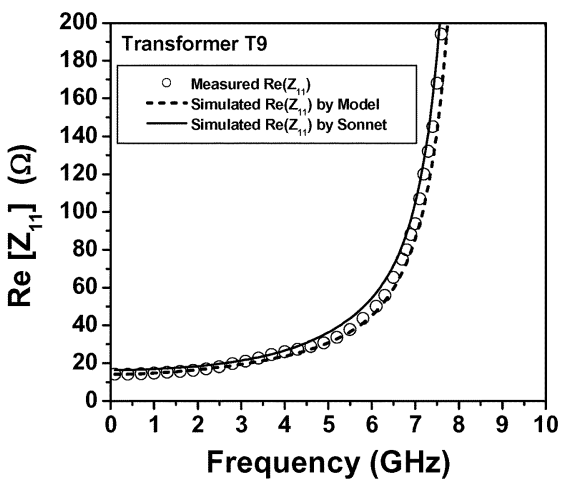

(a)

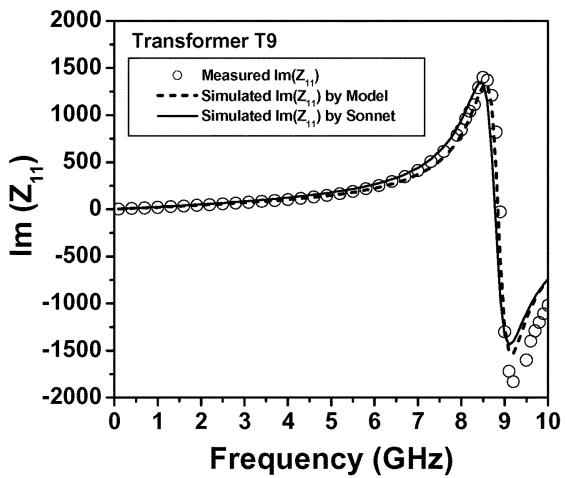

(c)

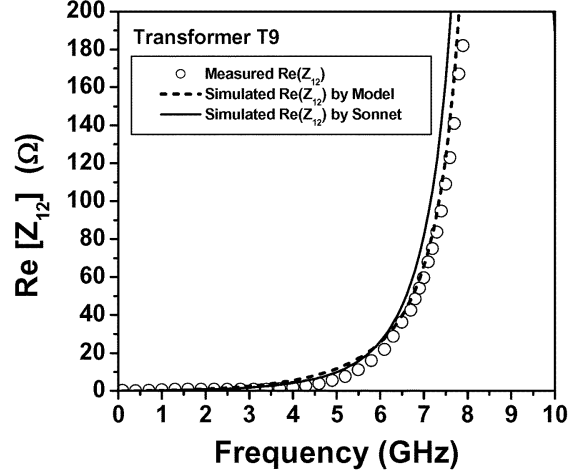

(b)

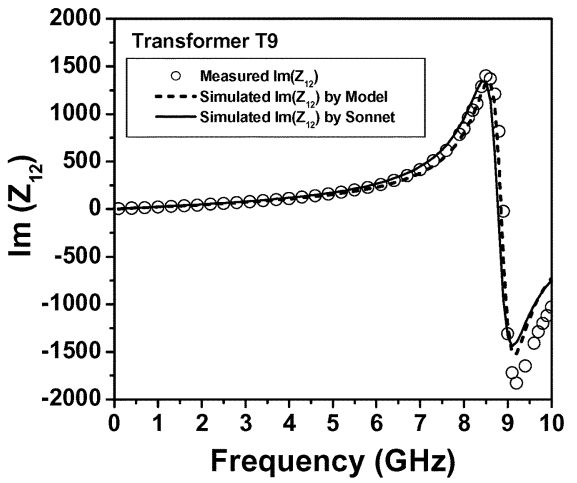

(d)

Fig. 6. Measured, modeled, and simulated: (a) $\operatorname{Re}\left(Z_{11}\right)$, (b) $\operatorname{Re}\left(Z_{12}\right)$, (c) $\operatorname{Im}\left(Z_{11}\right)$, and (d) $\operatorname{Im}\left(Z_{12}\right)$ versus frequency characteristics of the SMIS transformer T9 before the backside ICP etching.

where $Q_{1}$ [see (5)] and $Q_{2}\left(=\omega L_{2-\text { eff }} / R_{2-\text { eff }}=\right.$ $\left(\omega L_{s 2-\mathrm{eff}} / R_{s 2-\mathrm{eff}}\right) \times\left(R_{p 2} /\left(R_{p 2}+\right.\right.$ $\left.\left.\left[\left(\omega L_{s 2-\mathrm{eff}} / R_{s 2-\mathrm{eff}}\right)^{2}+1\right] R_{s 2-\mathrm{eff}}\right)\right) \times\left(1-\left(R_{s 2-\mathrm{eff}}^{2}\left(C_{p 2}+\right.\right.\right.$ $\left.\left.\left.\left.C_{s 2}\right) / L_{s 2-\text { eff }}\right)-\omega^{2} L_{s 2-\text { eff }}\left(C_{p 2}+C_{s 2}\right)\right)\right)$ represent the equivalent single-port (i.e., one port is short with the other coil open) $Q$-factor of the primary and secondary coil inductors, respectively, of the transformer. In addition, expressions of the magnetic-coupling factor $k_{\mathrm{Im}}$ and the resistive-coupling factor $k_{\mathrm{Re}}$ are as follows:

$$
\begin{aligned}
k_{\operatorname{Im}} & =\operatorname{Im}\left(Z_{12}\right) / \sqrt{\operatorname{Im}\left(Z_{11}\right) \cdot \operatorname{Im}\left(Z_{22}\right)} \\
& =L_{M} / \sqrt{L_{1-\mathrm{eff}} \cdot L_{2-\mathrm{eff}}} \\
k_{\operatorname{Re}} & =\operatorname{Re}\left(Z_{12}\right) / \sqrt{\left[\operatorname{Re}\left(Z_{11}\right) \cdot \operatorname{Re}\left(Z_{22}\right)\right]} \\
& =R_{M} / \sqrt{R_{1-\mathrm{eff}} \cdot R_{2-\mathrm{eff}}} .
\end{aligned}
$$

Once the $G_{A \max }$ of a transformer is obtained, its minimum noise figure $\mathrm{NF}_{\min }$ can be expressed as follows [34]:

$$
\begin{aligned}
\mathrm{NF}_{\text {min }} & =10 \log \left(\frac{1}{G_{A \max }}\right) \\
& =10 \log \left(L_{\min }\right) \\
& =10 \log \left(\frac{1}{k-\sqrt{k^{2}-1}}\right) \\
& =10 \log \left(\frac{1}{1+2\left(x-\sqrt{x^{2}+x}\right)}\right)
\end{aligned}
$$

where $G_{A \max }, L_{\min }$, and $k\left(=\left(1-\left|S_{11}\right|^{2}-\left|S_{22}\right|^{2}+\mid S_{11} S_{22}-\right.\right.$ $\left.\left.\left.S_{12} S_{21}\right|^{2}\right) /\left(2\left|S_{12} S_{21}\right|\right)\right)$ represent maximum available power gain, minimum power loss, and stability factor, respectively. Clearly, increasing $R_{p 1}$ and $R_{p 2}$ (i.e., increasing $R_{\text {sub1 } 1}$ and $R_{\text {sub2}}$ ) leads to a larger $Q_{1}$ and $Q_{2}$, i.e., a smaller $x$, and, therefore, a higher $G_{A \max }$ and a lower $\mathrm{NF}_{\min }$ (or $L_{\min }$ ). This explains why backside ICP etching can improve the $Q_{1}, Q_{2}$, $G_{A \text { max }}$, and $\mathrm{NF}_{\text {min }}$ of a transformer effectively.

\section{RESULTS AND DisCUSSIONS}

\section{A. Dimension Effects on SMIS Transformers}

The frequency-dependent $S$-parameter measurements were performed from 0.1 to $40 \mathrm{GHz}$ by an Agilent's $8510 \mathrm{C}$ vector network analyzer. $S$-parameters of a dummy open structure both before and after the backside ICP etching were measured for pad deembedding. In addition, $S$-parameters of a set of dummy through structures (with transmission-line width of 5,10 , and $20 \mu \mathrm{m}$ ) both before and after the backside ICP etching were measured for the purpose of extracting the transmission-line parameters $Z_{C}$ (characteristic impedance) and $\gamma$ (propagation constant). After deembedding the probe-pad parasitics of the dummy through structures, per-unit-length transmission-line parameters $Z_{C}$ and $\gamma$ (corresponding to widths of 5,10, and $20 \mu \mathrm{m}$ ) can be evaluated [35], [36]. Then, transformers with various device sizes and interconnect lengths can be individually deembedded with the application of the interconnect scalability.

In the following, we discuss the dimension effects on the SMIS transformers. Table II shows a detailed comparison of the extracted parameters between two-layer, four-layer, and six- 
TABLE II

DetaIled Comparison of the Extracted Parameters BetweEn Two-Layer, Four-LAYER, AND SiX-LAYer SMIS TRANSFORMERS (ON NORMAL SiLICON SUBSTRATE) With VARIOUS INNER DimENSIONS $\left(50 \times 50 \mu \mathrm{m}^{2}, 100 \times 100 \mu \mathrm{m}^{2}\right.$, AND $\left.150 \times 150 \mu \mathrm{m}^{2}\right)$

\begin{tabular}{|c|c|c|c|c|c|c|c|c|c|c|c|c|c|c|}
\hline TF No. & $\begin{array}{c}\text { Inner } \\
\text { Dimension } \\
\left(\mu \mathrm{m}^{2}\right)\end{array}$ & $\begin{array}{c}\text { Overall } \\
\text { Dimension } \\
\left(\mu \mathrm{m}^{2}\right)\end{array}$ & $\begin{array}{l}\text { Metal } \\
\text { Width } \\
(\mu \mathrm{m})\end{array}$ & $\begin{array}{c}\text { Coil } \\
\text { Spacing } \\
(\mu \mathrm{m})\end{array}$ & $\begin{array}{l}\text { Metal } \\
\text { Layers }\end{array}$ & $\begin{array}{c}\mathrm{f}_{\mathrm{SR}} \\
(\mathrm{GHZ})\end{array}$ & $\begin{array}{c}\text { frequency } \\
(\mathrm{GHz})\end{array}$ & $\mathrm{Q}_{1}$ & $\mathrm{Q}_{2}$ & $\mathrm{k}_{\mathrm{Im}}$ & $\mathrm{k}_{\mathrm{Re}}$ & $\mathrm{x}$ & $\mathrm{G}_{\mathrm{Amax}}$ & $\begin{array}{l}\mathrm{NF}_{\text {min }} \\
\text { (dB) }\end{array}$ \\
\hline \multirow{2}{*}{$\mathrm{T} 1$} & \multirow{6}{*}{$150 \times 150$} & \multirow{6}{*}{$170 \times 170$} & \multirow{6}{*}{10} & & 2 & \multirow{2}{*}{28.2} & 20 & 4.669 & 4.453 & 0.966 & 0.766 & $2.07 \times 10^{-2}$ & 0.751 & 1.245 \\
\hline & & & & & (M6-M5) & & 25 & 1.901 & 1.807 & 0.936 & 0.981 & $9.23 \times 10^{-3}$ & 0.825 & 0.833 \\
\hline \multirow{2}{*}{$\mathrm{T} 2$} & & & & & 1 & \multirow{2}{*}{15.3} & 10 & 4.761 & 4.589 & 1.01 & 0.72 & $2.11 \times 10^{-2}$ & 0.749 & 1.256 \\
\hline & & & & & (M6-M3) & & 15 & 0.246 & 0.245 & 0.975 & 0.997 & $5.59 \times 10^{-2}$ & 0.861 & 0.649 \\
\hline \multirow{2}{*}{ T3 } & & & & & 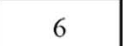 & \multirow{2}{*}{11.3} & 8 & 4.65 & 4.688 & 1.006 & 0.88 & $9.92 \times 10^{-3}$ & 0.82 & 0.864 \\
\hline & & & & & (M6-M1) & & 10 & 2.191 & 2.154 & 0.996 & 0.981 & $6.71 \times 10^{-3}$ & 0.849 & 0.711 \\
\hline \multirow{3}{*}{$\mathrm{T} 4$} & \multirow{5}{*}{$100 \times 100$} & \multirow{5}{*}{$120 \times 120$} & \multirow{5}{*}{10} & \multirow{5}{*}{5} & & \multirow{3}{*}{$\geq 40$} & 30 & 4.644 & 5.028 & 0.901 & 0.828 & $1.6 \times 10^{-2}$ & 0.777 & 1.097 \\
\hline & & & & & $\frac{2}{(M 6-M 5)}$ & & 36 & 2.67 & 3.283 & 0.884 & 0.975 & $6.41 \times 10^{-3}$ & 0.852 & 0.695 \\
\hline & & & & & & & 40 & 1.309 & 1.481 & 0.913 & 0.983 & $1.27 \times 10^{-2}$ & 0.799 & 0.977 \\
\hline \multirow{2}{*}{$\mathrm{T} 5$} & & & & & 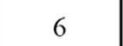 & \multirow{2}{*}{16.6} & 10 & 4.305 & 4.384 & 1.014 & 0.65 & $2.91 \times 10^{-2}$ & 0.712 & 1.475 \\
\hline & & & & & (M6-M1) & & 15 & 1.356 & 1.404 & 0.993 & 0.986 & $9.59 \times 10^{-3}$ & 0.822 & 0.849 \\
\hline \multirow{2}{*}{ T6 } & \multirow{6}{*}{$50 \times 50$} & \multirow{6}{*}{$56 \times 56$} & \multirow{6}{*}{3} & & 2 & \multirow{6}{*}{$\geq 40$} & 20 & 4.348 & 4.418 & 0.329 & 0.081 & $4.77 \times 10^{-1}$ & 0.275 & 5.6 \\
\hline & & & & & (M6-M5) & & 30 & 5.171 & 5.379 & 0.295 & 0 & $4.12 \times 10^{-1}$ & 0.298 & 5.252 \\
\hline \multirow{2}{*}{ T7 } & & & & & 7 & & 20 & 4.124 & 4.079 & 0.55 & 0.037 & $1.97 \times 10^{-1}$ & 0.423 & 3.734 \\
\hline & & & & & (M6-M3) & & 40 & 1.624 & 2.553 & 1.133 & 0.369 & $1.58 \times 10^{-1}$ & 0.460 & 3.371 \\
\hline \multirow{2}{*}{ T8 } & & & & & 6 & & 30 & 2.443 & 2.98 & 1.053 & 0.54 & $8.47 \times 10^{-2}$ & 0.563 & 2.493 \\
\hline & & & & & & & 40 & 0.65 & 0.678 & 0.992 & 0.986 & $2.01 \times 10^{-2}$ & 0.754 & 1.226 \\
\hline
\end{tabular}

layer SMIS transformers (on normal silicon substrate) with various inner dimensions $\left(50 \times 50 \mu \mathrm{m}^{2}, 100 \times 100 \mu \mathrm{m}^{2}\right.$, and $150 \times 150 \mu \mathrm{m}^{2}$ ). From the results of transformers T1-T5, we can see that decreasing the inner dimension or the layer numbers will increase $f_{\mathrm{SR}}$ of the primary and secondary coils of the transformer. In addition, in the frequency range of $36-40 \mathrm{GHz}$, high $k_{\operatorname{Im}}$ of $0.884-0.913$, high $k_{\mathrm{Re}}$ of 0.975-0.983, and high $G_{A \max }$ of 0.852-0.799 (or low $\mathrm{NF}_{\min }$ of $0.695-0.977 \mathrm{~dB}$ ) were achieved for transformer T4. To the best of the authors' knowledge, this is the best result of transformers on silicon in the $K a$-band (26-40 GHz) ever reported.

For higher frequency applications, scaled-down SMIS transformers should be adopted. However, the performances of the scaled-down SMIS transformers are restricted by the limitations set by the fabrication process. For example, reducing the dimension of a transformer will increase the etching depth-to-width ratio (if the area to be etched is roughly equal to the overall dimension of the transformer), which leads to incomplete etching. A feasible solution is to fix the layout area enclosed by the test pads of each device in the testkey [see the dash line in Fig. 3(a)], such as $350 \mu \mathrm{m} \times 300 \mu \mathrm{m}$. Then, optimize the backside ICP process which focuses on this specific $(350 \mu \mathrm{m} \times$ $300 \mu \mathrm{m}$ ) large-size exposed area. The price to be paid is the waste of the layout area if the size of the device is small. Fortunately, this problem does not exist when the process is applied to RFICs. This is because we can include several smallsize passive devices within an exposed area for ICP etching [25]. Besides, for a specific RF-CMOS process, the vertical distance between the metal layers is fixed, i.e., it cannot be scaled. This makes it harder for the scaled-down SMIS transformers to achieve high $k_{\operatorname{Im}}$ and $k_{\mathrm{Re}}$ at the same time in the very high fre- quencies of interest. A feasible solution is to adopt the M6, CTM (which is between M6 and M5), and M5 as the metal layers of the SMIS transformers because the vertical distance between them is smaller [26]. In the frequency range within $100 \mathrm{GHz}$, it is found that, by carefully finely tuning the inner dimension, metal width, metal layers and by proceeding with the full-wave simulation with commercial EM tools, such as Sonnet Software's Sonnet, high-performance SMIS transformers can still be achieved. Table III presents a summary of the Sonnet's simulated results of a set of SMIS transformers for $70-100-\mathrm{GHz}$ RFIC applications. Very good $G_{A \max }(\geq 0.8)$ was achieved for all of the transformers at the targeted frequencies. This demonstrates that the SMIS transformer is also very promising for 70-100-GHz RFIC applications.

\section{B. Substrate Effects on SMIS Transformers}

Fig. 7(a) shows the measured isolation $\left(S_{21}\right)$ versus frequency characteristics of a dummy open device before and after the backside ICP etching. As shown in Fig. 7(a), $S_{21}$ improvements of $20.6 \mathrm{~dB}$ (from -40.4 to $-61 \mathrm{~dB}$ ) and $15.7 \mathrm{~dB}$ (from -40 to $-55.7 \mathrm{~dB}$ ) were achieved at $5.2 \mathrm{and} 8 \mathrm{GHz}$, respectively, mainly due to the reduction of the parasitic capacitance through the substrate achieved by the substrate etching. Fig. 7(b) shows the measured $Q_{1}$ and $L_{1-\text { eff }}$ both before and after the backside ICP etching of the SMIS transformer T9. $Q$-factor increases of $102 \%$ (from 4.96 to 10.03 ) and $23.2 \%$ (from 2.24 to 2.76 ) were achieved at 5.2 and $8 \mathrm{GHz}$, respectively, for the transformer after the backside ICP etching.

Fig. 7(c) shows the measured $k_{\operatorname{Im}}$ and $k_{\text {Re }}$ versus frequency characteristics of the SMIS transformer T9 both before and after the backside ICP etching. Clearly, perfect $k_{\mathrm{Im}}(\sim 1)$ for fre- 
TABLE III

SUMMARY OF THE SimUlATEd Results OF A SET OF SMIS TRANSFORMERS FOR 70-100-GHz RFIC APPLICATIONS

\begin{tabular}{|c|c|c|c|c|c|c|c|c|c|c|c|c|c|c|}
\hline TF No. & $\begin{array}{c}\text { Inner } \\
\text { Dimension } \\
\left(\mu \mathrm{m}^{2}\right)\end{array}$ & $\begin{array}{c}\text { Overall } \\
\text { Dimension } \\
\left(\mu \mathrm{m}^{2}\right)\end{array}$ & $\begin{array}{c}\text { Metal } \\
\text { Width } \\
(\mu \mathrm{m})\end{array}$ & $\begin{array}{c}\text { Coil } \\
\text { Spacing } \\
(\mu \mathrm{m})\end{array}$ & $\begin{array}{c}\text { Metal } \\
\text { Layers }\end{array}$ & $\begin{array}{c}\mathrm{f}_{\mathrm{SR}} \\
(\mathrm{GHZ})\end{array}$ & $\begin{array}{c}\text { frequency } \\
(\mathrm{GHz})\end{array}$ & $\mathrm{Q}_{1}$ & $\mathrm{Q}_{2}$ & $\mathrm{k}_{\mathrm{Im}}$ & $\mathrm{k}_{\mathrm{Re}}$ & $\mathrm{x}$ & $\mathrm{G}_{\mathrm{Amax}}$ & $\begin{array}{l}\mathrm{NF}_{\min } \\
(\mathrm{dB})\end{array}$ \\
\hline \multirow{2}{*}{$\mathrm{T} 10$} & \multirow{2}{*}{$30 \times 30$} & \multirow{2}{*}{$36 \times 36$} & \multirow{2}{*}{3} & \multirow{2}{*}{3} & \multirow{6}{*}{$\begin{array}{c}6 \\
\text { (M6-M1) }\end{array}$} & \multirow{2}{*}{89} & 70 & 7.065 & 7.065 & 1 & 0.639 & $1.18 \times 10^{-2}$ & 0.805 & 0.94 \\
\hline & & & & & & & 80 & 4.239 & 4.239 & 1 & 0.964 & $3.74 \times 10^{-3}$ & 0.885 & 0.531 \\
\hline \multirow{2}{*}{ T11 } & \multirow{2}{*}{$30 \times 30$} & \multirow{2}{*}{$33 \times 33$} & \multirow{2}{*}{1.5} & \multirow{2}{*}{1.5} & & \multirow{2}{*}{94.8} & 80 & 4.625 & 4.625 & 1.156 & 0.844 & $9.82 \times 10^{-3}$ & 0.820 & 0.859 \\
\hline & & & & & & & 90 & 1.75 & 1.75 & 1.01 & 0.99 & $4.85 \times 10^{-3}$ & 0.870 & 0.604 \\
\hline \multirow{2}{*}{ T12 } & \multirow{2}{*}{$25 \times 25$} & \multirow{2}{*}{$28 \times 28$} & \multirow{2}{*}{1.5} & \multirow{2}{*}{1.5} & & \multirow{2}{*}{$\geq 100$} & 90 & 5.667 & 5.667 & 1.125 & 0.813 & $8.21 \times 10^{-3}$ & 0.834 & 0.8 \\
\hline & & & & & & & 100 & 3.067 & 3.067 & 1.01 & 0.98 & $3.75 \times 10^{-3}$ & 0.885 & 0.532 \\
\hline
\end{tabular}

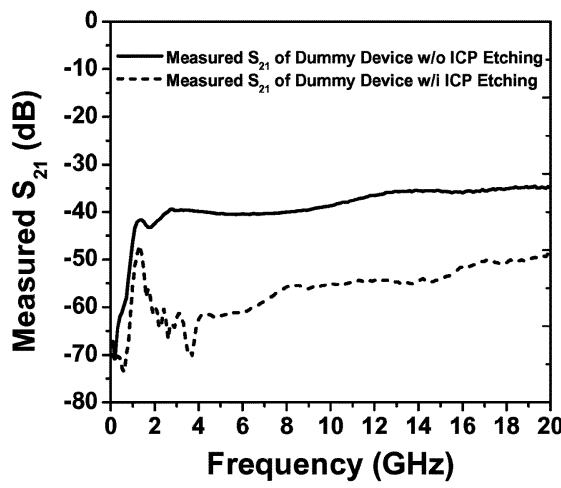

(a)

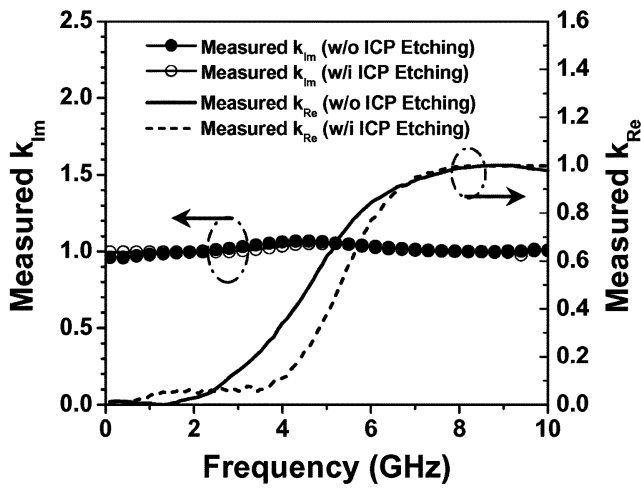

(c)

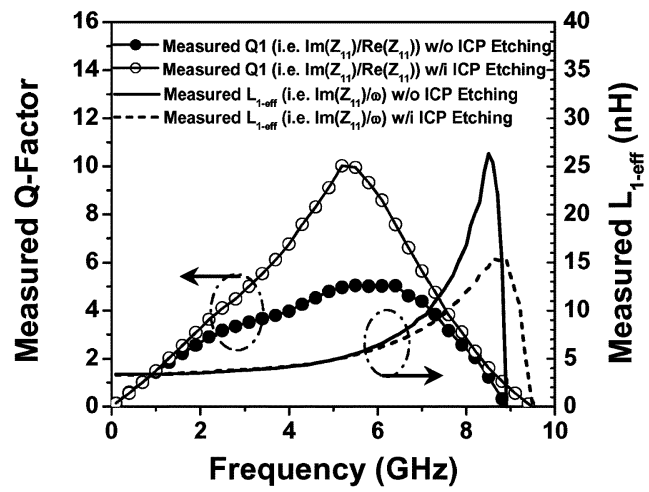

(b)

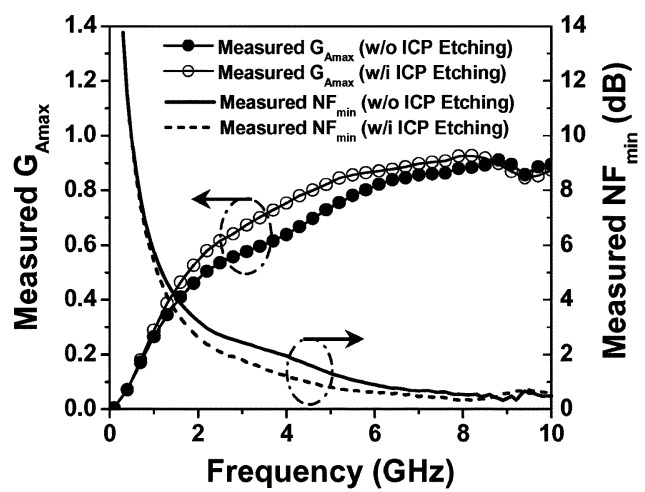

(d)

Fig. 7. (a) Measured isolation $\left(S_{21}\right)$ versus frequency characteristics of a dummy open device before and after the backside ICP etching. The measured: (b) $Q_{1}$ and $L_{1-\text { eff }}$ of the primary coil, (c) $k_{\mathrm{Im}}$ and $k_{\mathrm{Re}}$, and (d) $G_{A \max }$ and $\mathrm{NF}_{\min }$ versus frequency characteristics of the SMIS transformer T9 both before and after the backside ICP etching.

quencies from 0.1 to $10 \mathrm{GHz}$ was achieved both before and after the backside ICP etching mainly because the equivalent VD of this transformer was roughly zero [26]. In addition, high $k_{\mathrm{Re}} \geq 0.9$ was obtained for frequencies greater than $6.7 \mathrm{GHz}$ both before and after the backside ICP etching. The results of high $k_{\mathrm{Im}}$ and $k_{\mathrm{Re}}$ are attributed to the proposed transformer structure which exhibits nearly perfect coupling characteristics at high frequencies, that is $Z_{12}=Z_{21} \sim Z_{11} \sim Z_{22}$.

Fig. 7(d) shows the measured $G_{A \max }$ and $\mathrm{NF}_{\min }$ versus frequency characteristics of the SMIS transformer T9 both before and after the backside ICP etching. For the transformer before the backside ICP etching, good $G_{A \max }$ of 0.76 and 0.88 and $\mathrm{NF}_{\min }$ of 1.22 and $0.55 \mathrm{~dB}$ were achieved at 5.2 and $8 \mathrm{GHz}$, respectively, mainly due to the perfect $k_{\mathrm{Im}}$ and the high $k_{\mathrm{Re}} . G_{A \max }$ increases of $11.8 \%$ (from 0.76 to 0.85 ) and $4.5 \%$ (from 0.88 to 0.92 ) and $\mathrm{NF}_{\text {min }}$ decreases of $0.49 \mathrm{~dB}$ (from 1.22 to $0.73 \mathrm{~dB}$ ) and $0.19 \mathrm{~dB}$ (from 0.55 to $0.36 \mathrm{~dB}$ ) were achieved at 5.2 and $8 \mathrm{GHz}$, respectively, for the transformer after the backside ICP etching. This means the backside ICP etching is effective in improving the $G_{A \text { max }}$ and $\mathrm{NF}_{\min }$ performances of transformers due to lower substrate-related loss (i.e., larger $R_{\mathrm{sub} 1}, R_{\mathrm{sub} 2}, R_{m s 1 i}$, and $R_{m s 2 i}$ ).

Table IV shows a detailed comparison of the extracted parameters of the SMIS transformer T9, the traditional vertically stacked transformer [see Fig. 4(a) and (b)], the traditional bifilar transformer [see Fig. 4(c) and (d)] in this study, and the bifilar transformers in [19] and [21]. The $G_{A \max }$ of $0.845(5.2 \mathrm{GHz})$ and $0.92(8 \mathrm{GHz})$ of our SMIS transformer T9 are better than those $(0.76$ and 0.77$)$ of the bifilar transformer on porous silicon with overall dimensions of $280 \mu \mathrm{m} \times 280 \mu \mathrm{m}$ [19] and 
TABLE IV

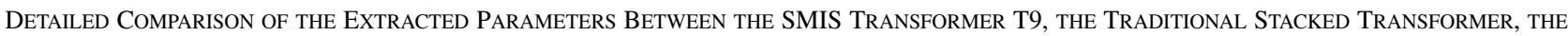
TRADITIONAL BIFILAR TRANSFORMER IN THIS PAPER AND THE BIFILAR TRANSFORMERS IN [19] AND [21]

\begin{tabular}{|c|c|c|c|c|c|c|c|c|c|c|c|c|c|}
\hline & $\begin{array}{l}\text { Transformer } \\
\text { Structure }\end{array}$ & $\begin{array}{c}\text { Overall } \\
\text { Dimension } \\
\left(\mu \mathrm{m}^{2}\right)\end{array}$ & Technology & $\begin{array}{c}\text { substrate } \\
\text { resistivity } \\
(\Omega \cdot \mathrm{cm})\end{array}$ & $\begin{array}{l}\text { frequency } \\
(\mathrm{GHz})\end{array}$ & $\mathrm{Q}_{1}$ & $\mathrm{Q}_{2}$ & $\mathrm{k}_{\mathrm{Im}}$ & $\mathrm{k}_{\mathrm{Re}}$ & $\mathrm{x}$ & $\mathrm{G}_{\mathrm{Amax}}$ & $\mathrm{L}_{\min }$ & $\begin{array}{c}\mathrm{NF}_{\min } \\
(\mathrm{dB})\end{array}$ \\
\hline \multirow{2}{*}{$\begin{array}{l}\text { K. Chong } \\
{[19]}\end{array}$} & \multirow{2}{*}{$\begin{array}{l}\text { Thick }(3.02 \mu \mathrm{m}) \text { Bifilar } \\
\text { (on porous Si substrate) }\end{array}$} & \multirow{2}{*}{$280 \times 280$} & \multirow{2}{*}{ NA } & \multirow{2}{*}{ NA } & 5.2 & 9.10 & 9.10 & 0.75 & 0.38 & $1.83 \times 10^{-2}$ & 0.76 & 1.31 & 1.17 \\
\hline & & & & & 8 & 6.69 & 6.69 & 0.83 & 0.67 & $1.81 \times 10^{-2}$ & 0.77 & 1.31 & 1.16 \\
\hline \multirow{4}{*}{$\begin{array}{l}\text { K. T. Ng } \\
{[21]}\end{array}$} & \multirow{2}{*}{$\begin{array}{l}\text { Thin }(0.85 \mu \mathrm{m}) \text { Bifilar } \\
\text { (on normal Si substrate) }\end{array}$} & \multirow{4}{*}{$300 \times 300$} & \multirow{4}{*}{ NA } & \multirow{2}{*}{10} & 5.2 & 2.86 & 2.62 & 0.62 & 0.60 & $1.96 \times 10^{-1}$ & 0.42 & 2.36 & 3.73 \\
\hline & & & & & 8 & 1.62 & 1.33 & 0.59 & 0.76 & $3.16 \times 10^{-1}$ & 0.34 & 2.92 & 4.66 \\
\hline & \multirow{2}{*}{$\begin{array}{l}\text { Thin }(0.85 \mu \mathrm{m}) \text { Bifilar } \\
\text { (on quartz substrate) }\end{array}$} & & & \multirow{2}{*}{$\infty$} & 5.2 & 6.14 & 6.52 & 0.61 & 0.17 & $6.55 \times 10^{-2}$ & 0.60 & 1.66 & 2.20 \\
\hline & & & & & 8 & 7.62 & 8.14 & 0.59 & 0.14 & $4.55 \times 10^{-2}$ & 0.66 & 1.53 & 1.84 \\
\hline \multirow{10}{*}{ This Work } & \multirow{2}{*}{$\begin{array}{l}\text { Six-layer SMIS (T9) } \\
\text { (on normal Si substrate) }\end{array}$} & \multirow{4}{*}{$170 \times 240$} & \multirow{4}{*}{$\begin{array}{l}0.18 \mu \mathrm{m} \\
\mathrm{CMOS}\end{array}$} & \multirow{4}{*}{10} & 5.2 & 4.96 & 4.96 & 1.06 & 0.67 & $1.97 \times 10^{-2}$ & 0.76 & 1.32 & 1.22 \\
\hline & & & & & 8 & 2.24 & 2.25 & 1.00 & 0.99 & $3.97 \times 10^{-3}$ & 0.88 & 1.13 & 0.55 \\
\hline & \multirow{2}{*}{$\begin{array}{c}\text { Six-layer SMIS (T9) } \\
\text { (w/i backside ICP etching) }\end{array}$} & & & & 5.2 & 10.03 & 10.05 & 1.05 & 0.46 & $7.10 \times 10^{-3}$ & 0.85 & 1.18 & 0.73 \\
\hline & & & & & 8 & 2.76 & 2.61 & 1.00 & 0.99 & $1.71 \times 10^{-3}$ & 0.92 & 1.09 & 0.36 \\
\hline & $\begin{array}{c}\text { Vertically Stacked } \\
\text { (on normal Si substrate) } \\
\end{array}$ & \multirow{2}{*}{$240 \times 240$} & \multirow{2}{*}{$\begin{array}{l}0.18 \mu \mathrm{m} \\
\mathrm{CMOS}\end{array}$} & \multirow{2}{*}{10} & \multirow{2}{*}{2} & 2.69 & 2.01 & 0.93 & 0.42 & $1.70 \times 10^{-1}$ & 0.45 & 2.23 & 3.49 \\
\hline & \begin{tabular}{|c|} 
Vertically Stacked \\
(w/i backside ICP etching) \\
\end{tabular} & & & & & 4.04 & 3.02 & 0.93 & 0.40 & $7.91 \times 10^{-2}$ & 0.57 & 1.74 & 2.41 \\
\hline & \multirow{2}{*}{$\begin{array}{l}\text { Thick }(3.05 \mu \mathrm{m}) \text { Bifilar } \\
\text { (on normal Si substrate) }\end{array}$} & \multirow{4}{*}{$230 \times 215$} & \multirow{4}{*}{$\begin{array}{c}0.35 \mu \mathrm{m} \\
\mathrm{BiCMOS}\end{array}$} & \multirow{4}{*}{10} & 5.2 & 5.55 & 6.63 & 0.69 & 0.52 & $4.16 \times 10^{-2}$ & 0.67 & 1.50 & 1.76 \\
\hline & & & & & 8 & 3.78 & 4.68 & 0.66 & 0.49 & $9.56 \times 10^{-2}$ & 0.54 & 1.84 & 2.65 \\
\hline & \multirow{2}{*}{$\begin{array}{c}\text { Thick }(3.05 \mu \mathrm{m}) \text { Bifilar } \\
\text { (w/i backside ICP etching) }\end{array}$} & & & & 5.2 & 10.11 & 10.33 & 0.71 & 0.22 & $1.81 \times 10^{-2}$ & 0.76 & 1.31 & 1.16 \\
\hline & & & & & 8 & 11.96 & 12.65 & 0.70 & 0.14 & $1.32 \times 10^{-2}$ & 0.79 & 1.26 & 1.00 \\
\hline
\end{tabular}

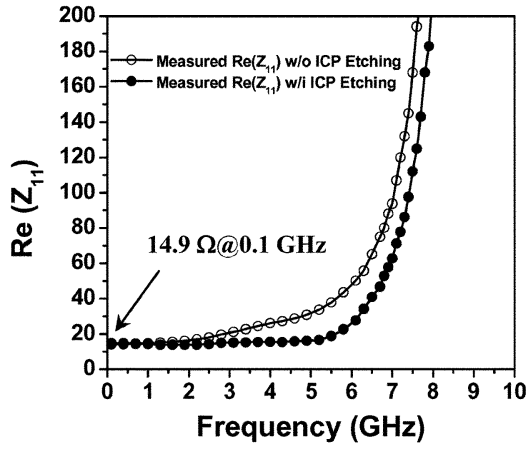

(a)

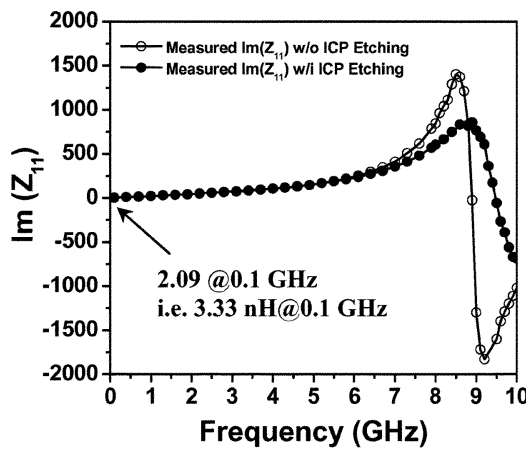

(c)

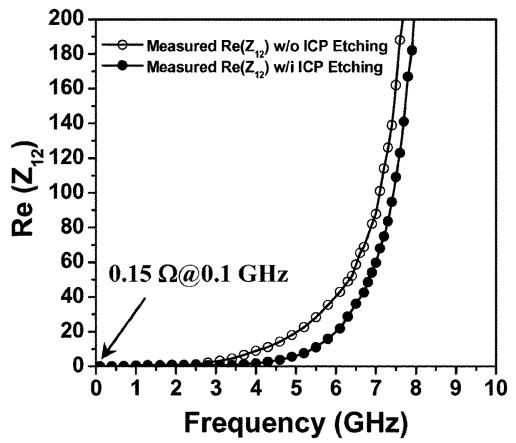

(b)

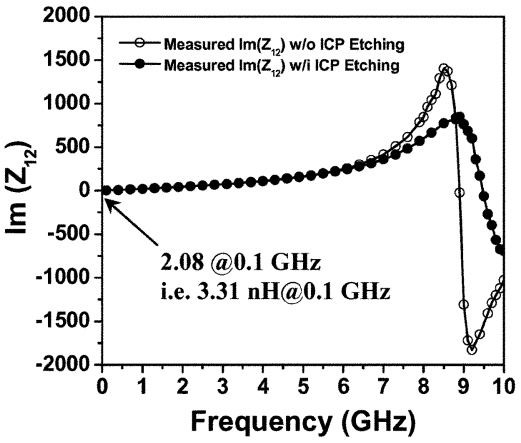

(d)

Fig. 8. Measured: (a) $\operatorname{Re}\left(Z_{11}\right)$, (b) $\operatorname{Re}\left(Z_{12}\right)$, (c) $\operatorname{Im}\left(Z_{11}\right)$, and (d) $\operatorname{Im}\left(Z_{12}\right)$ versus frequency characteristics of the SMIS transformer T9 both before and after the backside ICP etching.

better than those ( 0.60 and 0.66$)$ of the bifilar transformer on a quartz substrate with overall dimensions of $300 \mu \mathrm{m} \times 300 \mu \mathrm{m}$ [21]. From the results shown in Tables I-IV, we can conclude that, from the viewpoint of $k_{\mathrm{Im}}, k_{\mathrm{Re}}$, and $G_{A \max }\left(\mathrm{NF}_{\min }\right)$, the SMIS transformer structure performs better than the traditional stacked structure and the traditional bifilar structure do mainly 


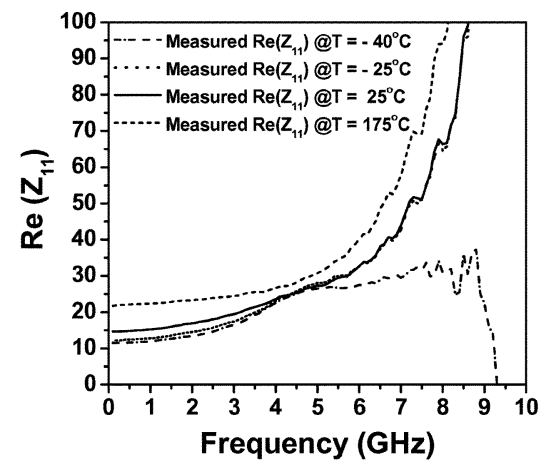

(a)

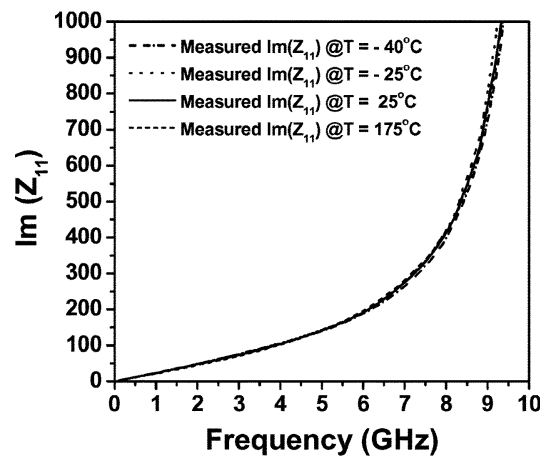

(c)

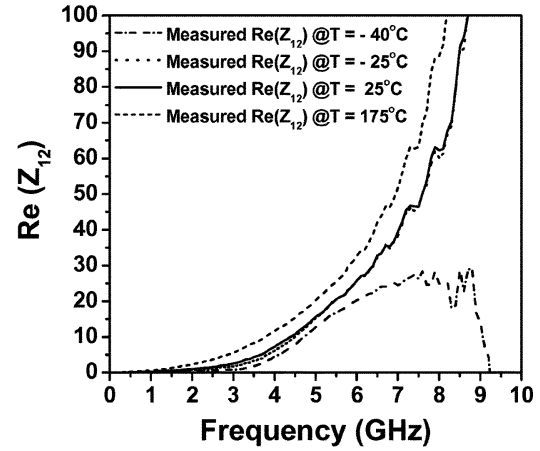

(b)

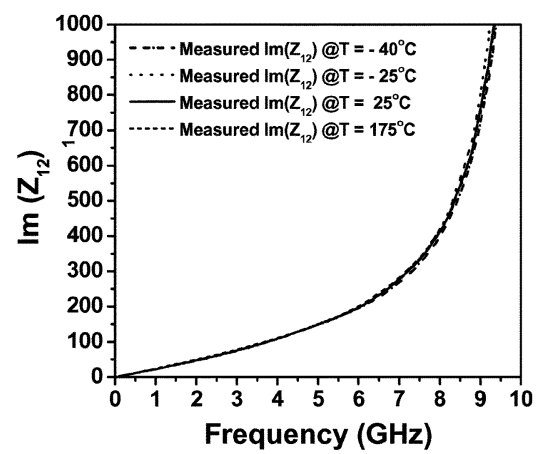

(d)

Fig. 9. Measured: (a) $\operatorname{Re}\left(Z_{11}\right)$, (b) $\operatorname{Re}\left(Z_{12}\right)$, (c) $\operatorname{Im}\left(Z_{11}\right)$, and (d) $\operatorname{Im}\left(Z_{12}\right)$ versus frequency characteristics of a six-layer SMIS transformer with metal width of $9.5 \mu \mathrm{m}$ and overall dimensions of $160 \mu \mathrm{m} \times 230 \mu \mathrm{m}$ before the backside ICP etching at various temperatures $\left(-40^{\circ} \mathrm{C},-25^{\circ} \mathrm{C}, 25^{\circ} \mathrm{C}\right.$, and $\left.175^{\circ} \mathrm{C}\right)$.

due to the nearly perfect $k_{\operatorname{Im}}(\sim 1)$ and high $k_{\text {Re }}$ in the frequency band of interest. That is exactly why the SMIS transformer can achieve state-of-the-art $G_{A \max }$ and $\mathrm{NF}_{\min }$ performances even though its metal thicknesses (top metal: $0.99 \mu \mathrm{m}$; others: $0.53 \mu \mathrm{m}$ ) are thinner than those (top metal: $3.02 \mu \mathrm{m}$; underpass metal: $1.52 \mu \mathrm{m}$ ) in [19]. The reason why the performance of the micomachined devices in [11]-[16] is not included in Table IV for comparison is explained as follows. The work in [11]-[13] and [15], [16] is related to micromachined inductors, which are different from the micromachined transformers studied in this paper. In addition, while part of [14] is related to micromachined transformers, no information such as the performances of $k_{\mathrm{Im}}, k_{\mathrm{Re}}$, and $G_{A \text { max }}$ are available. Therefore, it is hard to fairly compare the performances of the transformers in this work with those in [14].

In addition, it is found that, for both the SMIS transformer and the traditional stacked transformer after the backside ICP etching, $k_{\text {Im }}$ remains nearly unchanged at all frequencies while $k_{\mathrm{Re}}$ decreases within a medium frequency range. These phenomena are explained as follows.

Fig. 8(a) and (b) shows the measured real part of $Z_{11}\left(\operatorname{Re}\left(Z_{11}\right)\right)$ and real part of $Z_{12}\left(\operatorname{Re}\left(Z_{12}\right)\right)$, respectively, of the SMIS transformer T9 both before and after the backside ICP etching at room temperature. As can be seen from Fig. 8(b), the measured $\operatorname{Re}\left(Z_{12}\right)$ (i.e., $\left.R_{M}\right)$ at $0.1 \mathrm{GHz}$ is about $0.15 \Omega$, which is much smaller than that $(14.75 \Omega)$ of the measured $\operatorname{Re}\left(Z_{11}\right)$ (i.e., $\left.R_{1-\text { eff }}\right)$ due to very weak resistive coupling at low frequencies. Moreover, at a medium frequency range roughly from 3 to $6 \mathrm{GHz}$, the measured $\operatorname{Re}\left(Z_{11}\right)$ and $\operatorname{Re}\left(Z_{12}\right)$ after the backside ICP etching is close to those measured at
$0.1 \mathrm{GHz}$ due to weak silicon substrate-related loss. However, both of the measured $\operatorname{Re}\left(Z_{11}\right)$ and $\operatorname{Re}\left(Z_{12}\right)$ before the backside ICP etching obviously surpass those measured after the backside ICP etching due to the enhanced silicon substrate loss and the enhanced resistive coupling that stems from the silicon substrate, respectively. This explains why, in Fig. 7(c), the measured $k_{\mathrm{Re}}$ after the backside ICP etching is lower than that before the backside ICP etching in the frequency range of 3-6 GHz. In addition, for frequencies greater than $6 \mathrm{GHz}$, the SMIS transformer T9 exhibits nearly perfect resistive coupling, i.e., $\operatorname{Re}\left(Z_{11}\right) \cong \operatorname{Re}\left(Z_{12}\right)$, whether before or after the backside ICP etching. This explains why, in Fig. 7(c), for frequencies greater than $6 \mathrm{GHz}$, the measured $k_{\mathrm{Re}}$ before and after the backside ICP etching are almost the same. Fig. 8(c) and (d) shows the measured imaginary part of $Z_{11}\left(\operatorname{Im}\left(Z_{11}\right)\right)$ and the imaginary part of $Z_{12}\left(\operatorname{Im}\left(Z_{12}\right)\right)$, respectively, of the SMIS transformer T9 both before and after the backside ICP etching at room temperature. The measured $L_{1-\text { eff }}$ (i.e., $\operatorname{Im}\left(Z_{11}\right) / \omega$ ) at $0.1 \mathrm{GHz}$ is about $3.33 \mathrm{nH}$, which is nearly equal to that $\left(3.31 \mathrm{nH}\right.$ ) of the measured $L_{M}$ (i.e., $\operatorname{Im}\left(Z_{12}\right) / \omega$ ) at $0.1 \mathrm{GHz}$ due to nearly perfect magnetic coupling of the six-layer SMIS transformer structure. Moreover, in all of the frequencies in interest, the SMIS transformer exhibits nearly perfect magnetic coupling, i.e., $\operatorname{Im}\left(Z_{11}\right) \cong \operatorname{Im}\left(Z_{12}\right)$, whether before or after the backside ICP etching. This explains why, in Fig. 7(c), the measured $k_{\mathrm{Im}}$ before and after the backside ICP etching is about 1 in all of the frequencies in interest.

Fig. 9(a) and (b) shows the measured $\operatorname{Re}\left(Z_{11}\right)$ and $\operatorname{Re}\left(Z_{12}\right)$, respectively, of a six-layer SMIS transformer before the backside ICP etching at various temperatures (i.e., $-40^{\circ} \mathrm{C},-25^{\circ} \mathrm{C}$, 
$25^{\circ} \mathrm{C}$, and $\left.175{ }^{\circ} \mathrm{C}\right)$. Metal width and overall dimension of this transformer are $9.5 \mu \mathrm{m}$ and $160 \mu \mathrm{m} \times 230 \mu \mathrm{m}$, respectively. As can be seen, the measured $\operatorname{Re}\left(Z_{11}\right)$ (i.e., $\left.R_{1-e f f}\right)$ increases with the increase of temperature mainly due to the positive temperature coefficient of the series metal resistance $R_{s 1} \| R_{\mathrm{sk} 1}$. The measured temperature dependence of $R_{1-\mathrm{eff}}$ at low frequencies (i.e., $R_{s 1} \| R_{\mathrm{sk} 1}$ ) is linear. The corresponding temperature coefficient is $3.96 \times 10^{-3} /{ }^{\circ} \mathrm{C}$ at $0.1 \mathrm{GHz}$, which is very close to the result $\left(3.9 \times 10^{-3} /{ }^{\circ} \mathrm{C}\right)$ reported in the literature [37]. Fig. 9(c) and (d) shows the measured $\operatorname{Im}\left(Z_{11}\right)$ and $\operatorname{Im}\left(Z_{12}\right)$, respectively, of the six-layer SMIS transformer before the backside ICP etching at various temperatures (i.e., $-40{ }^{\circ} \mathrm{C},-25^{\circ} \mathrm{C}, 25^{\circ} \mathrm{C}$, and $\left.175^{\circ} \mathrm{C}\right)$. As can be seen, the temperature dependences of both $\operatorname{Im}\left(Z_{11}\right)$ and $\operatorname{Im}\left(Z_{12}\right)$ (i.e., $\omega L_{1-\text { eff }}$ and $\left.\omega L_{M}\right)$ are very weak. Therefore, the phenomenon that $G_{A \text { max }}$ decreases with increasing temperatures while $\mathrm{NF}_{\text {min }}$ increases with increasing temperatures (which is not shown here) can be explained by the positive temperature coefficient of $\operatorname{Re}\left(Z_{11}\right)$ and $\operatorname{Re}\left(Z_{22}\right)$ (i.e., $R_{1-\text { eff }}$ and $R_{2-\text { eff }}$ ), that is, an increase of temperature will increase $R_{1-\text { eff }}$ and $R_{2-\text { eff }}$, leading to a smaller $Q_{1}$ and $Q_{2}$, i.e., a larger $x$ and, therefore, a lower $G_{A \max }$ and a higher $\mathrm{NF}_{\min }$.

\section{CONCLUSION}

First, selective removal of the silicon underneath transformers based on the proposed backside ICP deep trench technology is demonstrated. The results show that the CMOS-compatible backside ICP postprocess is effective to improve the $Q$-factors and NF performances of transformers on silicon. Apparently, the proposed ICP technology is also capable of improving the isolation between RF/analog and digital circuits and thus paves a way for systems-on-chip. Second, a detailed analysis of the SMIS transformer structure both before and after the backside ICP etching is presented. Compared with the traditional bifilar and the traditional stacked transformer structures, the SMIS transformer structure exhibits better performance. These results show that the micromachined SMIS transformer structure is very promising for high-performance 5-GHz-band and even higher 24-100-GHz-band RFIC applications.

\section{ACKNOWLEDGMENT}

The authors are grateful for the supports of the Chip Implementation Center (CIC) for the transformer fabrication and National Nano Device Laboratories (NDL) for high-frequency measurements.

\section{REFERENCES}

[1] H. W. Chiu, S. S. Lu, and Y. S. Lin, "A $2.17 \mathrm{~dB} \mathrm{NF}, 5 \mathrm{GHz}$ band monolithic CMOS LNA with $10 \mathrm{~mW}$ DC power consumption on a thin $(20 \mu \mathrm{m})$ substrate," IEEE Trans. Microw. Theory Tech., vol. 53, no. 3, pp. 813-824, Mar. 2005.

[2] J. R. Long, "A low-voltage 5.1-5.8-GHz image-reject down-converter RF IC," IEEE J. Solid-State Circuits, vol. 35, no. 9, pp. 1320-1328, Sep. 2000.

[3] C. H. Doan, S. Emami, and A. M. Niknejad, "Millimeter-wave CMOS design," IEEE J. Solid-State Circuits, vol. 40, no. 1, pp. 144-155, Jan. 2005.

[4] H. Shigematsu, T. Hirose, F. Brewer, and M. Rodwell, "Millimeterwave CMOS circuit design," IEEE Trans. Microw. Theory Tech., vol. 53, no. 2, pp. 472-477, Feb. 2005.
[5] T. O. Dickson, M. A. LaCroix, S. Boret, D. Gloria, R. Beekens, and S. P. Voinigescu, "30-100 GHz inductors and transformers for millimeter-wave (Bi)CMOS integrated circuits," IEEE Trans. Microw. Theory Tech., vol. 53, no. 1, pp. 123-134, Jan. 2005.

[6] K. W. Yu, Y. L. Lu, D. C. Chang, V. Liang, and M. F. Chang, " $K$-band low-noise amplifiers using $0.18 \mu \mathrm{m}$ CMOS technology," IEEE Microw. Wireless Compon. Lett., vol. 14, no. 3, pp. 106-108, Mar. 2004.

[7] K. Kwok and H. C. Luong, "Ultra-low-voltage high-performance CMOS VCOs using transformer feedback," IEEE J. Solid-State Circuits, vol. 40, no. 3, pp. 652-660, Mar. 2005.

[8] A. W. L. Ng and H. C. Luong, "A $1-\mathrm{V} 17 \mathrm{GHz} 5 \mathrm{~mW}$ quadrature CMOS VCO based on transformer coupling," in Proc. IEEE Int. Solid-State Circuits Conf., San Francisco, CA, pp. 198-199.

[9] D. J. Cassan and J. R. Long, "A 1-V transformer-feedback low-noise amplifier for 5-GHz wireless LAN in $0.18 \mu \mathrm{m}$ CMOS," IEEE J. SolidState Circuits, vol. 38, no. 3, pp. 427-435, Mar. 2003.

[10] J. N. Burghartz, D. C. Edelstein, K. A. Jenkins, and Y. H. Kwark, "Spiral inductors and transmission lines in silicon technology using copper-damascene interconnects and low-loss substrates," IEEE Trans. Microw. Theory Tech., vol. 45, no. 10, pp. 1961-1968, Oct. 1997.

[11] J. Y.-C Chang, A. A. Abidi, and M. Gaitan, "Large suspended inductors on silicon and their use in a $2 \mu \mathrm{m}$ CMOS RF amplifier," IEEE Electron Device Lett., vol. 14, no. 5, pp. 246-248, May 1993.

[12] H. Lakdawala, X. Zhu, H. Luo, S. Santhanam, L. R. Carley, and G. K. Fedder, "Micromachined high- $Q$ inductors in a $0.18 \mu \mathrm{m}$ copper interconnect low- $k$ dielectric CMOS process," IEEE J. Solid-State Circuits, vol. 37, no. 3, pp. 394-403, Mar. 2002.

[13] M. Ozgur, M. E. Zaghloul, and M. Gaitan, "Optimization of backside micromachined CMOS inductors for RF applications," in Proc. IEEE Int. Symp. Circuits Syst., Geneva, Switzerland, May 2000, pp. V-185-V-188.

[14] R. P. Ribas, J. Lescot, J.-L. Leclercq, J. M. Karam, and F. Ndagijimana, "Micromachined microwave planar spiral inductors and transformers," IEEE Trans. Microw. Theory Tech., vol. 48, no. 8, pp. 1326-1335, Aug. 2000.

[15] P. G. M. Baltus, A. G. Wagemans, R. Dekker, A. Hoogstraate, H. Maas, A. Tombeur, and J. van Sinderen, "A $3.5 \mathrm{~mW} 2.5 \mathrm{GHz}$ diversity receiver and a $1.2 \mathrm{~mW} 3.6 \mathrm{GHz}$ VCO in silicon-on-anything," IEEE J. Solid-State Circuits, vol. 33, no. 12, pp. 2074-2079, Dec. 1998.

[16] J. W. Lin, C. C. Chen, and Y. T. Cheng, "A robust high- $Q$ micromachined RF inductor for RFIC applications," IEEE Trans. Electron Devices, vol. 52, no. 7, pp. 1489-1496, Jul. 2005.

[17] Y. H. Xie, M. R. Frei, A. J. Becker, C. A. King, D. Kossives, L. T. Gomez, and S. K. Theiss, "An approach for fabricating high-performance inductors on low-resistivity substrates," IEEE J. Solid-State Circuits, vol. 33, no. 9, pp. 1433-1438, Sep. 1998.

[18] H. S. Kim, D. Zheng, A. J. Becker, and Y. H. Xie, "Spiral inductors on Si p/p+ substrates with resonant frequency of $20 \mathrm{GHz}$," IEEE Electron Device Lett., vol. 22, no. 6, pp. 275-277, Jun. 2001.

[19] K. Chong and Y. H. Xie, "High-performance on-chip transformers," IEEE Electron Device Lett., vol. 26, no. 8, pp. 557-559, Aug. 2005.

[20] C. Y. Lee, T. S. Chen, C. H. Kao, J. D. S. Deng, C. C. Yen, Y. K. Lee, J. C. Kuo, J. F. Chang, G. W. Huang, K. M. Chen, and T. S. Duh, "A simple systematic procedure of Si-based spiral inductor design," in IEEE Proc. RFIC Conf., Jun. 2004, pp. 619-622.

[21] K. T. Ng, B. Rejaei, and J. N. Burghartz, "Substrate effects in monolithic RF transformers on silicon," IEEE Trans. Microw. Theory Tech., vol. 50, no. 1, pp. 377-383, Jan. 2002.

[22] Y. S. Lin, H. B. Liang, T. Wang, and S. S. Lu, "Temperature dependence of noise figure of monolithic RF transformers on a thin (20 $\mu \mathrm{m})$ silicon substrate," IEEE Electron Device Lett., vol. 26, no. 3, pp. 208-211, Mar. 2005.

[23] T. Wang, Y. S. Lin, and S. S. Lu, "An ultra-low-loss and broadband micomachined RF inductor for RFIC input-matching applications," IEEE Trans. Electron Devices, vol. 53, no. 3, pp. 568-570, Mar. 2006.

[24] T. Wang, H. C. Chen, H. W. Chiu, Y. S. Lin, G. W. Huang, and S. S. Lu, "Micromachined CMOS LNA and VCO By CMOS compatible ICP deep trench technology," IEEE Trans. Microw. Theory Tech., vol. 54 , no. 2 , pp. $580-588$, Feb. 2006.

[25] T. Wang, C. H. Chen, Y. S. Lin, and S. S. Lu, "A micro-machined 2-10 GHz CMOS distributed amplifier by CMOS compatible ICP deep trench technology," IEEE Electron Device Lett., vol. 27, no. 4, pp. 291-293, Apr. 2006.

[26] H. M. Hsu, "Implementation of high-coupling and broadband transformer in RFCMOS technology," IEEE Trans. Electron Devices, vol. 52, no. 7, pp. 1410-1414, Jul. 2005. 
[27] Y. S. Lin, "Implementation of perfect-magnetic-coupling ultra-lowloss transformer in RFCMOS technology," IEEE Electron Device Lett., vol. 26, no. 11, pp. 832-835, Nov. 2005.

[28] S. Kodali and D. J. Allstot, "A symmetrical miniature 3-D inductor," in Proc. IEEE Int. Symp. Circuits Syst., 2003, vol. 1, pp. 89-92.

[29] W. Z. Chen and K. C. Hsu, "Miniaturized 3-dimensional transformer design," in Proc. IEEE Custom Integr. Circuits Conf., 2005, pp. 285-288.

[30] W. Z. Chen and W. H. Chen, "Symmetrical Stacked Inductor," U.S. Patent 6870457.

[31] Y. S. Lin, H. B. Liang, T. Wang, and S. S. Lu, "An analysis of perfect-magnetic-coupling ultra-low-loss micromachined SMIS RF transformers for RFIC applications," in Proc. IEEE Radio Wireless Symp., San Diego, CA, pp. 55-58.

[32] A. Zolfaghari, A. Chan, and B. Razavi, "Stacked inductors and transformers in CMOS technology," IEEE J. Solid-State Circuits, vol. 36, no. 4, pp. 620-628, Apr. 2001.

[33] A. C. Watson, D. Melendy, P. Francis, K. Hwang, and A. Weisshaar, "A comprehensive compact-modeling methodology for spiral inductors in silicon-based RFICs," IEEE Trans. Microw. Theory Tech., vol. 52, no. 3, pp. 849-857, Mar. 2004.

[34] B. Razavi, RF Microelectronics. Englewood Cliffs, NJ: Prentice-Hall, 1998, pp. 39-48.

[35] C. B. Sia, B. H. Ong, K. S. Yeo, J. G. Ma, and M. A. Do, "Accurate and scalable RF interconnect model for silicon-based RFIC applications," IEEE Trans. Microw. Theory Tech., vol. 53, no. 9, pp. 3035-3044, Sep. 2006.

[36] A. M. Mangan, S. P. Voinigescu, M. T. Yang, and M. Tazlauanu, "Deembedding transmission line measurements for accurate modeling of IC designs," IEEE Trans. Electron Devices, vol. 53, no. 2, pp. 235-241, Feb. 2006.

[37] S. A. Campbell, The Science and Engineering of Microelectronic Fabrication, 2nd ed. Oxford, U.K.: Oxford Univ. Press, 2001, p. 585.

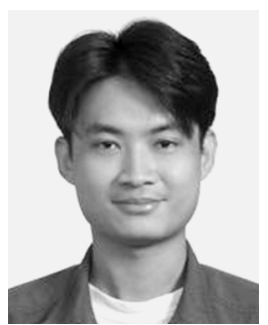

Hsiao-Bin Liang was born in Taipei, Taiwan, R.O.C., on August 7, 1979. He received the B.S. degree in electronic engineering from Chung-Yuan Christian University, Chung Li, Taiwan, R.O.C., in 2001, the M.S. degree in electrical engineering from National Chi Nan University, Puli, Taiwan, R.O.C., in 2003, and is is currently working toward the Ph.D. degree at National Chi Nan University. His thesis was related to the analysis of the kink phenomena of MOSFETs and the design of dual-band SiGe low-noise amplifiers.

His current research is focused on the design of RF inductors/transformers and related RF integrated circuit topics for wireless communication.

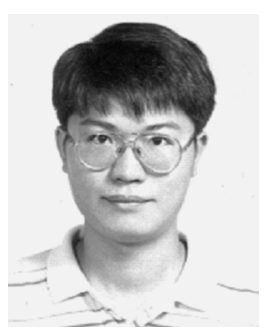

Yo-Sheng Lin (M'02-SM'06) was born in Puli, Taiwan, R.O.C., on October 10, 1969. He received the Ph.D. degree in electrical engineering from National Taiwan University, Taipei, Taiwan, R.O.C., in 1997. His Ph.D. degree concerned the fabrication and study of GaInP-InGaAs-GaAs-doped channel field-effect transistors and their applications on monolithic microwave integrated circuits (MMICs).

He joined the Taiwan Semiconductor Manufacturing Company (TSMC) in 1997 as a Principle Engineer for $0.35 / 0.32-\mu \mathrm{m}$ DRAM and $0.25-\mu \mathrm{m}$ embedded DRAM technology developments in the Integration Department of Fab-IV. Beginning in 2000, he was responsible for $0.18 / 0.15 / 0.13-\mu \mathrm{m}$ CMOS low-power device technology development with the Department of Device Technology and Modeling, Research and Development, and was promoted to Technical Manager in 2001. In August 2001, he joined the Department of Electrical Engineering, National Chi Nan University, Puli, Taiwan, R.O.C., where he is currently a Professor. From June to September, 2004, he was a Visiting Researcher with the High-Speed Electronics Research Department, Bell Laboratories, Lucent Technologies, Murray Hill, NJ. His current research interests are in the areas of characterization and modeling of RF active and passive devices (especially 30-100-GHz interconnections, inductors, and transformers for millimeter-wave (Bi)CMOS integrated circuits), and radio-frequency ICs/MMICs.

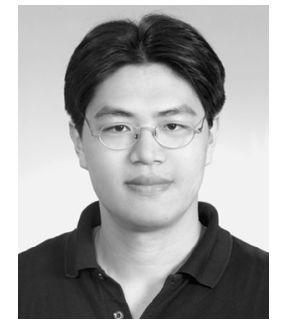

Chi-Chen Chen was born in Tainan, Taiwan, R.O.C., on February 10, 1975. He received the M.S. degree in electrical engineering from National Chi Nan University, Puli, Taiwan, R.O.C., in 2003, and is currently working toward the $\mathrm{Ph} . \mathrm{D}$ degree at National Chi Nan University. His thesis concerned radio-frequency (RF) monolithic low-noise amplifiers and mixers.

From 2003 to 2004, he was an Analog IC Design Engineer with the Anachip Corporation, Taipei, Taiwan, R.O.C. His current research is the design of RF transformers and RF front-ends for cellular applications.

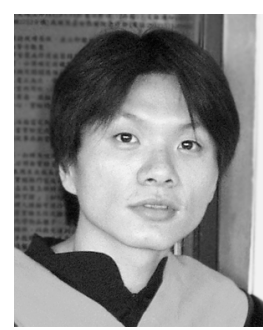

Po-Feng Yeh was born in Chang-Hua, Taiwan, R.O.C., on January 18, 1981. He received the M.S. degree in electrical engineering from National Chi Nan University, Puli, Taiwan, R.O.C., in 2006. His thesis concerned the design and implementation of 5-GHz-band voltage-controlled oscillators and high-performance varactors.

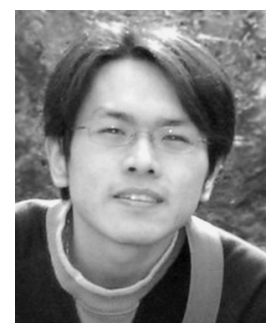

Yan-Ru Tzeng was born in Tainan, Taiwan, R.O.C., on September 11, 1981. He received the B.S. degree in electronic engineering from I-Shou University, Kaohsiung, Taiwan, R.O.C., in 2004, the M.S. degree in electrical engineering from National $\mathrm{Chi}$ Nan University, Puli, Taiwan, R.O.C., in 2006, and is currently working toward the Ph.D. degree in electrical engineering from National Cheng-Kung University, Tainan, Taiwan, R.O.C.

His research interests focus on RFIC design with an emphasis on optimization of passive elements, oscillators, and frequency synthesizers.

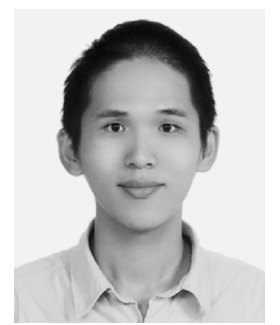

Tao Wang was born in Taipei, Taiwan, R.O.C., in 1980. He received the B.S. degree in electronics engineering from Chang Gung University, Taoyuan, Taiwan, R.O.C., in 2002, the M.S. degree in electronics engineering from National Taiwan University, Taipei, Taiwan, R.O.C., in 2004, and is currently working toward the Ph.D. degree in electronics engineering at the National Taiwan University.

His research interests are in the areas of radio-frequency integrated circuits and MEMS.

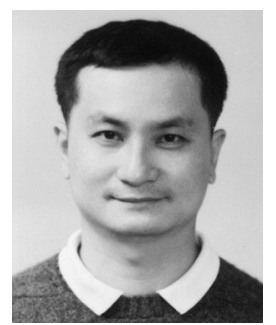

Shey-Shi Lu (S'89-M'91-SM'99) was born in Taipei, Taiwan, R.O.C., on October 12, 1962. He received the B.S. degree from the National Taiwan University, Taipei, Taiwan, R.O.C., in 1985, the M.S. degree from Cornell University, Ithaca, NY, in 1988, and the Ph.D. degree from the University of Minnesota at Minneapolis-St. Paul in 1991, all in electrical engineering. His thesis concerned the planar doped barrier hot-electron transistor, while his dissertation concerned the uniaxial stress effect on the AlGaAs-GaAs quantum-well/barrier structures.

In August 1991, he joined the Department of Electrical Engineering, National Taiwan University, where he is currently a Professor. His current research interests are in the areas of RFIC/monolithic microwave ICs, and micromachined $\mathrm{RF}$ components. 